\title{
DONCELlas (PUNA SEPTENTRIONAL, JuJuY, ARgENTINA): NuEVOS ENFOQUES \\ A PARTIR DEL ESTUDIO CERÁMICO Y DEL ANÁLISIS PALEODIETARIO
}

\author{
Martina Pérez y Violeta A. Killian Galván ${ }^{2}$
}

\section{* Introducción}

Resumen

En este trabajo, presentamos los resultados de dos líneas de investigación independientes: el análisis paleodietario a través de las relaciones de isótopos estables de carbono y nitrógeno sobre restos humanos y el análisis tecno-estilístico de los recipientes cerámicos, aplicadas al estudio de materiales de colecciones provenientes del área arqueológica

del río Doncellas (Puna Septentrional argentina). A partir de estos análisis, se han detectado similitudes y diferencias en distintos sectores del área arqueológica (poblado y sepulcros) en ambos tipo de muestras. El sector de sepulcros evidencia una ergología especial vinculada con la actividad textil. Este mismo sector presenta, entre otros bienes de prestigio, un conjunto de recipientes cerámicos de estilos foráneos como la Cultura Yavi, el Imperio inkaico o el área de yungas. A su vez, el análisis esqueletal de individuos provenientes de los sepulcros nos muestra una señal isotópica diferente con respecto a los individuos del poblado.

Palabras claves: puna - cerámica - isótopos estables - Doncellas.

\begin{abstract}
Here, we present the results of two independent lines of research: paleodiet analysis through stable isotope ratios of carbon and nitrogen in human bones and techno-stylistic analysis of ceramic vessels, applied to the study of collection materials from the archaeological site Río Doncellas (northwestern Puna, Argentina). From these analyses, similarities and differences have been detected in two sectors of the archaeological area (village and tombs) in both types of samples. Evidence from the tombs shows a relationship with the textile industry. Moreover, this same sector shows, among other prestige goods, a set of foreign ceramic container styles, including from the Yavi Culture, the Inca Empire and the Yungas. Evidence from the skeletal analysis of these individuals shows a different isotopic signal with respect to those from individuals in the village.

Key words: puna - pottery - stable isotopes - Doncellas. Recibido: julio 2011. Aceptado: enero 2012.
\end{abstract}

Este trabajo apunta a avanzar en el conocimiento general de la Localidad Arqueológica Río Doncellas (Depto. de Cochinoca, Jujuy) a partir de dos líneas de evidencia, el análisis morfo-estilístico de la cerámica y el análisis paleodietario de restos humanos. Con tal fin, se caracterizarán comparativamente dos sectores funcionalmente diferenciados: sector de sepulcros y sector del poblado, con el objetivo de detectar similitudes o diferencias en ambos tipos de muestras que permitan relacionar los aspectos sociales involucrados en los contextos funerarios.

Nuestra investigación, así como las realizadas previamente por otros investigadores, señala la existencia de diferentes patrones mortuorios, ya sea en la disposición del cuerpo, su acompañamiento o forma de inhumación. La intención de este trabajo es explicar las causas por las que se dio este comportamiento diferencial frente a la muerte. Proponemos evaluarlo desde un enfoque que considere las diferentes ocupaciones que tuvieron lugar, el potencial ganadero del área y su capacidad de funcionar como nodo en la escala macroregional.

Esta aproximación holística al mundo de los muertos nos permitirá discutir las características de los hábitos mortuorios como reflejo de las relaciones sociales que tuvieron lugar en el pasado, dada la presencia de una ergología destinada deliberadamente a la actividad fúnebre.

1 FFyL-UBA, INAPL 3 de febrero 1378 (C1426BJN), Ciudad Autónoma de Buenos Aires, ARGENTINA. E-mail: martinainesperez@hotmail.com

2 CONICET/Instituto de Geocronología y Geología Isotópica (INGEIS) - UBA. Pabellón INGEIS - Ciudad Universitaria (C1428EHA), Ciudad Autónoma de Buenos Aires, ARGENTINA. E-mail: violetakillian@gmail.com 


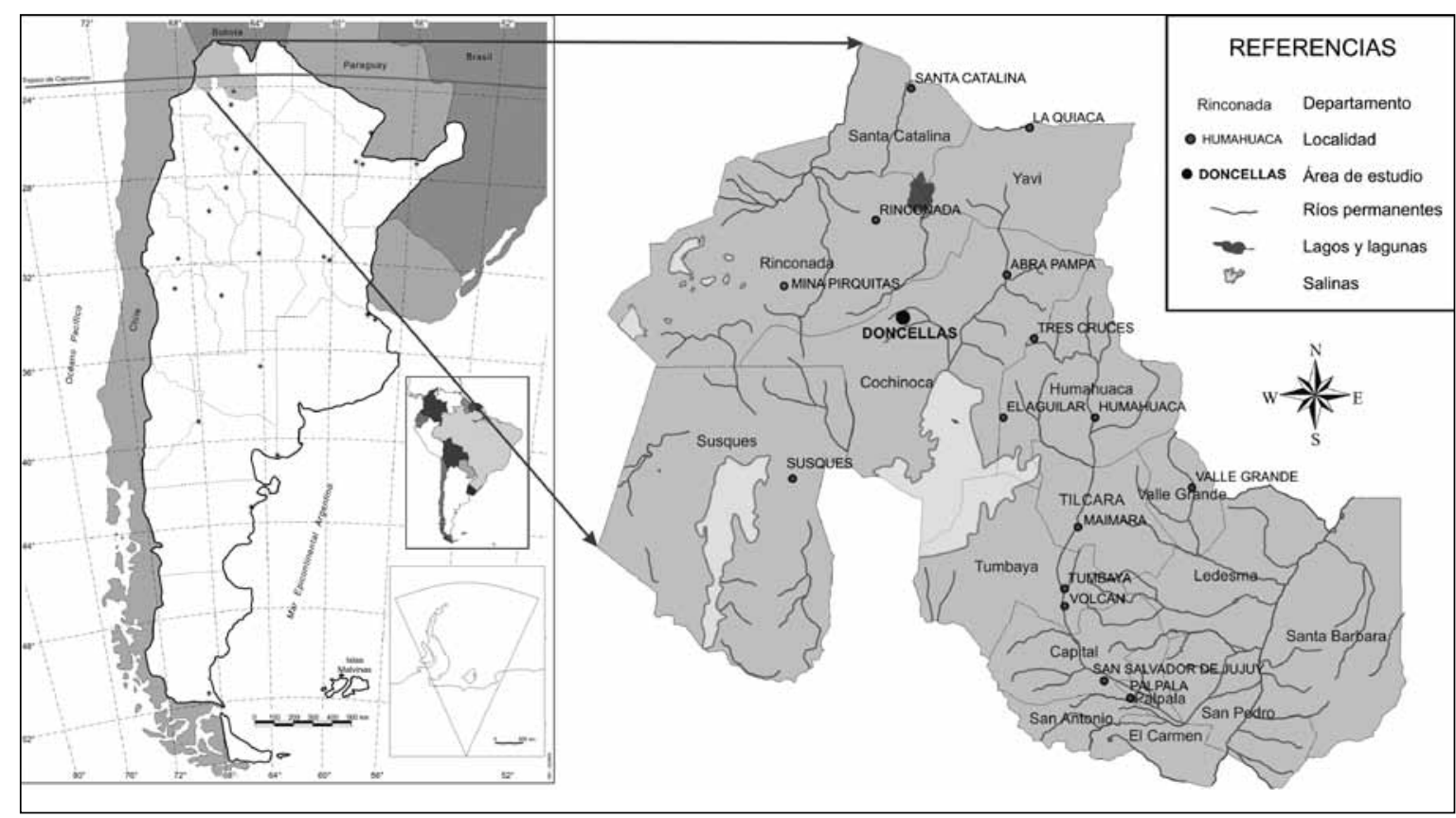

Figura 1. Mapa del área arqueológica del río Doncellas.

\section{* Área de estudio}

La Localidad Arqueológica Río Doncellas (Depto. de Cochinoca, provincia de Jujuy) se emplaza entre $22^{\circ} 49^{\prime} 12,28^{\prime \prime} \mathrm{S}$ y $66^{\circ} \mathrm{O} 3^{\prime} 54,89^{\prime \prime} \mathrm{O}$, conformando un rectángulo imaginario de 35 por $25 \mathrm{~km}$ (Figura 1). Se halla en un ambiente típico de Puna (Alfaro de Lanzone 1988). La cuenca central del área donde se emplaza la localidad Río Doncellas es aquella denominada "Guayatayoc-Miraflores" y el área cuenta con una amplia variación altitudinal (entre 1000 y 1500 m.s.n.m., sobre distancias relativamente cortas) con precipitaciones anuales que tienen rangos entre 100 y $300 \mathrm{~mm}$, aunque cuenta con recursos hídricos permanentes (Alfaro de Lanzone 1988). Los rasgos altitudinales y topográficos influyen también en las temperaturas medias (que pueden llegar a superar los $40^{\circ} \mathrm{C}$ ), las cuales varían sobre todo en el invierno. En el verano, la variación es menos extrema gracias a la mayor humedad y las heladas son frecuentes durante la noche y más predecibles entre abril y octubre (Ottonello de Reinoso y Ruthsatz 1982).

El semidesierto donde se emplaza este sector fue definido como estepa arbustiva puneña (Ruthatz y Movia
1975). En esta estepa, la disposición de vegetales se establece en formas de fajas (Ruthatz y Movia 1975), dada la disposición de cuencas alargadas de las cuales emergen importantes cordones montañosos. En las cuencas bajas, predominan las formaciones de estepa matorral y de pastizal. En cambio, a medida que se asciende por los faldeos montañosos, decrece la población arbustiva gracias a la mayor humedad. Asimismo, abundan las vegas pastas, inundadas durante todo el año (Cabrera 1957, Ruthsatz y Movia 1975).

Son escasos los lugares donde puede efectuarse la agricultura, lo que se agrava por la corta estación para el cultivo. Aun así, pueden cultivarse vegetales microtérmicos (quínoa, papa y otros tubérculos andinos) y maíz en algunos lugares muy prósperos. En lo que respecta a los herbívoros, los nichos ecológicos se encuentran bien delimitados. Esto implica el respeto por límites altimétricos, lo cual permite el pastoreo en lugares diferentes de acuerdo a la condición doméstica o silvestre del animal (Fernández y Panarello 1999-2001a). La ganadería de camélidos es posible gracias a las pasturas estacionales que se encuentran en los fondos de las cuencas, así como en las vegas de agua permanentes (Albeck 2001). En síntesis, el marco am- 


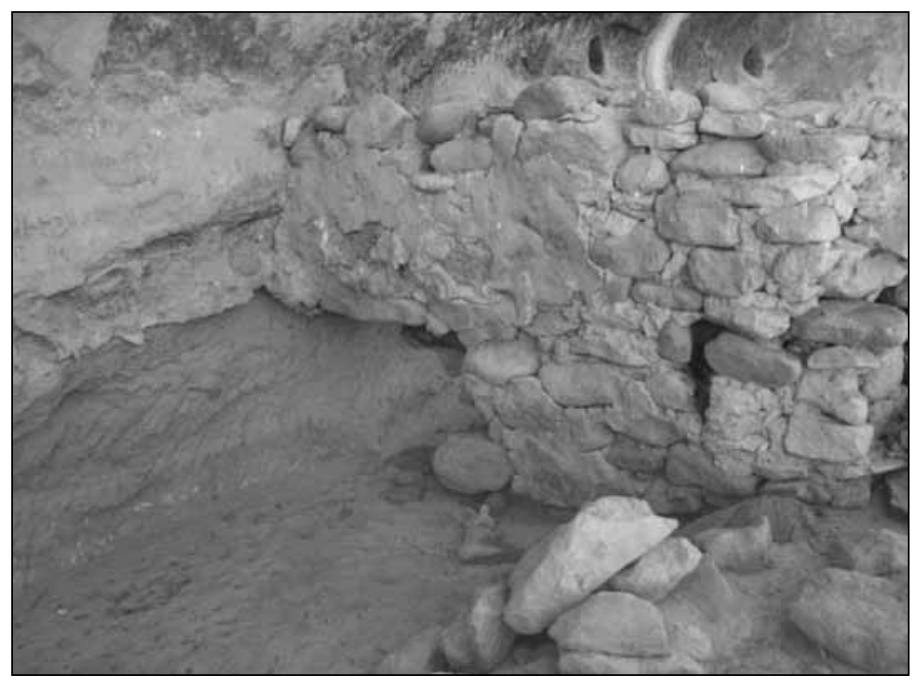

Figura 2. Ejemplo de Casa Tumba ubicada en el sector Farallones, Doncellas.

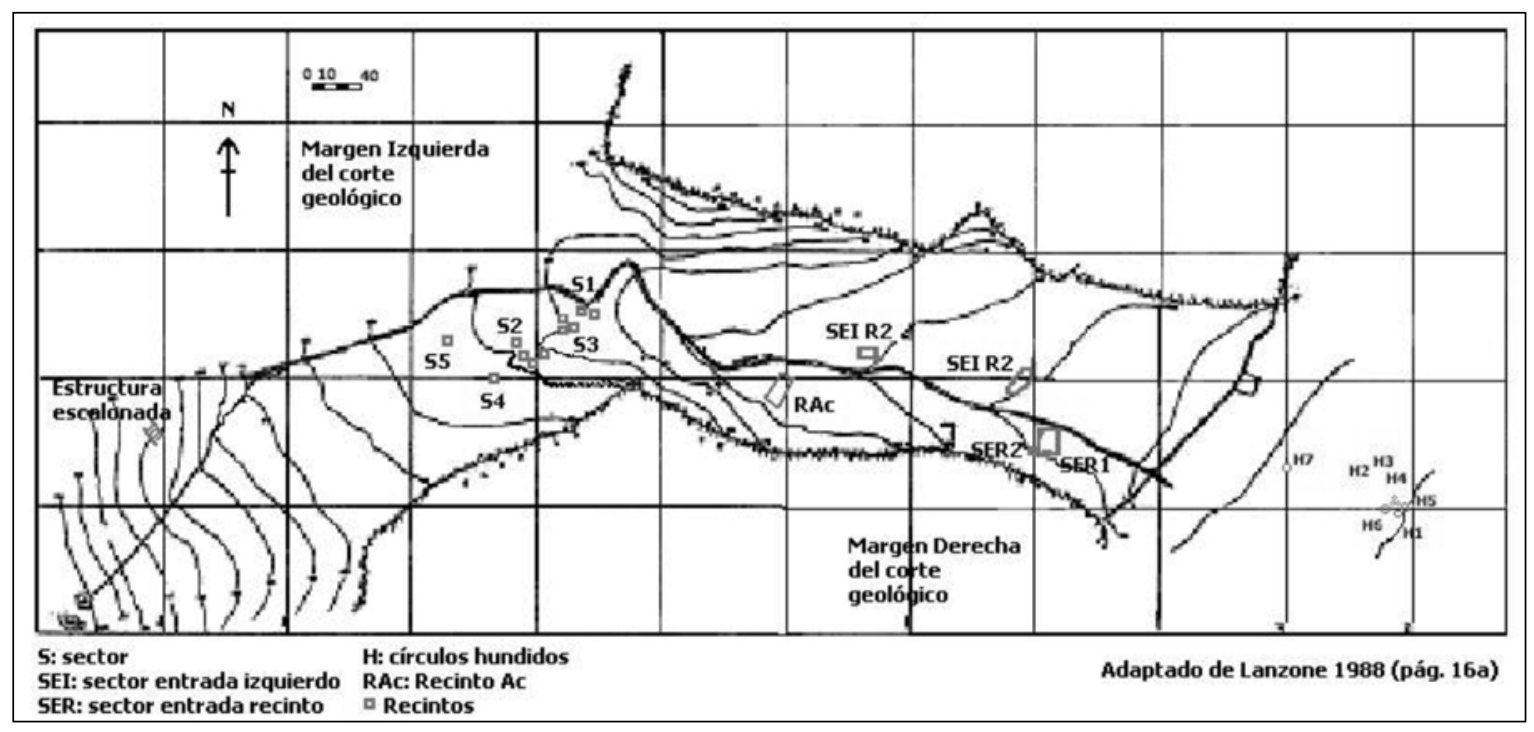

Figura 3. Croquis de la localidad arqueológica.

biental ha jugado un rol importante en los límites a la productividad tanto agrícola como pastoril. Esto debido a la importancia de la altitud y la humedad como factores que repercuten en la distribución y biomasa de las pasturas. De esta manera, la posición estratégica de la zona donde se emplaza la localidad ha permitido que las poblaciones que la ocuparon hicieran usufructo de los llanos y húmedos de alto valor económico para las sociedades pastoriles.
El área arqueológica se ha delimitado en diferentes sectores: las casas-pozo, en la entrada al mismo, el poblado principal y el sector de Farallones, a ambos lados del poblado. Los dos últimos alojan estructuras funerarias (sintetizadas en la tipología en Ottonello de García Reinoso y Krapovickas 1973) (Figura 2). Además, el yacimiento cuenta con andenes de cultivo y cuevas y aleros asociados, a distancias que no superan los $5 \mathrm{~km}$ (Figura 3). Los 


\begin{tabular}{|c|c|c|c|}
\hline Sector & Tipos de enterratorios & Fechado/material/procedencia & Bibliografía \\
\hline Casas-pozo & no registrados & $\mathrm{NO}$ & Alfaro de Lanzone 1988 \\
\hline \multirow{6}{*}{ Poblado } & párvulo en urna & \multirow{6}{*}{$\begin{array}{c}740 \pm 50 / \text { carbón vegetal / Recinto S.E.R. } 1 \\
310 \pm 50 / \text { carbón vegetal/ Recinto Ac }\end{array}$} & Alfaro de Lanzone 1988 \\
\hline & adulto en urna & & Alfaro de Lanzone 1988 \\
\hline & entierros secundarios de adultos & & Alfaro de Lanzone 1988 \\
\hline & elementos esqueletales aislados & & Alfaro de Lanzone 1988 \\
\hline & sepulcro de planta circular & & Alfaro de Lanzone 1988 \\
\hline & entierro directo múltiple & & Alfaro de Lanzone 1988 \\
\hline \multirow{3}{*}{ Farallones Sur } & sepulcro de planta semi-circular & \multirow{3}{*}{$\begin{array}{c}360 \pm 50 / \text { paja ichu/ Hallazgo } 3 \\
720 \pm 70 / \text { cordón vegetal / Yacimiento VII }\end{array}$} & \multirow{3}{*}{$\begin{array}{c}\text { Alfaro de Lanzone } 1988 \\
\text { Ottonello } 1973 \\
\text { Pérez de Micoú } 1996\end{array}$} \\
\hline & grupas tapiadas & & \\
\hline & casas tumba / chullpas & & \\
\hline $\begin{array}{l}\text { Farallones } \\
\text { Norte }\end{array}$ & entierro directo & $640 \pm 50 /$ carbón vegetal/ Hallazgo 2 & Alfaro de Lanzone 1988 \\
\hline \multirow{2}{*}{ Cuevas/aleros } & adulto en urna & \multirow{2}{*}{$\mathrm{NO}$} & Alfaro de Lanzone 1988 \\
\hline & adulto sin aclaración & & Casanova 1944 \\
\hline
\end{tabular}

Tabla 1. Tipología de sepulcros conforme procedencia y cronologías asociadas.

fechados radiocarbónicos ofrecen una cronología que ubica las ocupaciones entre ca. 740 y 310 años AP (Alfaro de Lanzone 1988 y Pérez de Micoú 1996). A su vez, la presencia de una moneda española de 1677 encontrada en el sitio durante las investigaciones de Vignati (1938), entre otros indicadores, refuerza la idea de una ocupación del poblado hasta tiempos hispánicos.

\section{* Antecedentes}

La primera cita que apunta a la inferencia de diferencias sociales entre los individuos que ocuparon el yacimiento, la hallamos en los trabajos de Casanova (1943). Casanova justifica esta apreciación por la presencia de tumbas con ajuares más abundantes y variados que otros. De todos modos, debemos destacar que hubo un sesgo en la recolección de los ítems arqueológicos dado que este investigador se circunscribió al sector de sepulcros, los cuales denominó Yacimientos. Bajo esta denominación, las más de 3 mil piezas encontradas, pasaron a conformar las actuales colecciones del Museo Etnográfico de Buenos Aires Juan Bautista Ambrosetti, FFyL-UBA (de ahora en adelante ME) y el Museo
Eduardo Casanova del Instituto Interdisiplinario de Tilcara en Jujuy FFyL-UBA (IIT). El paradigma de ese momento favoreció que se perdiera toda información contextual de muchos de los objetos encontrados, a lo cual contribuyeron las modalidades de trabajo de los museos de esa época.

Para los intereses de este trabajo, es importante señalar que Casanova en ningún momento parece tomar interés en el sector habitacional de Doncellas, por lo que no realiza ningún tipo de observaciones referentes a la variabilidad o no de ambos sectores.

Entre 1969 y 1971, Ottonello de García Reynoso realiza investigaciones en la zona y define a la cultura tardía Agua Caliente de Rachaite con el sitio de la cuenca del río Doncellas, donde señala la existencia de menhires, inhumaciones en cuevas, casas tumba, arquitectura doméstica y agrícola. A su vez, realiza el primer estudio del material cerámico y es quien propone la primera tipología de la cerámica de la aldea a partir de la recolección de superficie y a los materiales de excavación (Otonello 1973). Esta misma autora, cuantifica y caracteriza los patrones mortuorios ubicados en el sector de Sepulcros (Tabla 1). 
Pero no es hasta las investigaciones de Alfaro de Lanzone y Suetta (1976), que se identifican inhumaciones también en el sector del poblado (ver Tabla 1), aunque sin un énfasis particular en la reflexión sobre este comportamiento diferencial frente a la muerte. El aporte que introduce Alfaro de Lanzone es la relación entre el poblado y el sector de sepulcros, al afirmar que aquellos individuos que produjeron textiles de manera especializada, dedicando un recinto específico para esta actividad, eran inhumados en los farallones (Alfaro de Lanzone 1983). Los objetos que se recogieron en estas campañas fueron depositados en el INAPL y son los que forman la colección Doncellas perteneciente a esta institución.

Posteriormente, Pérez de Micou (1996) identifica otra diferencia entre ambos sectores, luego del análisis del material vegetal flexible de ambas colecciones. Las mismas obedecen principalmente a los aspectos tecnológicos de este tipo de manufacturas. Según la investigadora, esta diferenciación sustancial podría ser consecuencia de que las muestras provienen de un contexto depositacional diferente, ya que el material de Alfaro de Lanzone, a diferencia del de Casanova, no está asociado con enterratorios. Pero también podría obedecer a la utilización funcional diferencial de los distintos sectores del sitio o a la cronología diferente que demuestran los fechados absolutos.

En lo que respecta a los materiales textiles de Doncellas, los mismos han sido analizados por Rolandi de Perrot (1979). En su análisis, esta autora detecta una serie de técnicas involucradas en la producción local de estos bienes (como el teñido por reserva o íkat y la técnica de faz y urdimbre) y la presencia de una pieza de carácter foráneo ("altiplánico") con un diseño complejo de figuras geométricas en policromía que se distingue por la utilización de la técnica de faz de trama.

Por otra parte, en un trabajo dirigido a observar el potencial interpretativo de la colección Doncellas del ME, Egaña y colaboradores encuentran niveles de variabilidad intra e intertumbas y observan que hay individuos o grupos de individuos dentro de la sociedad que tienen acceso a ciertos bienes escasos y/o con una importancia simbólica social diferencial dentro del mismo contexto de la colección (Egaña et al. 2003).

\section{* Apartado metodológico}

Como ya se anticipó, este trabajo se ha realizado con materiales provenientes de excavaciones previas depositados en diferentes instituciones y gran parte de ellos pertenecientes a colecciones de museos. Los que no pertenecían a colecciones (parte del material de Alfaro de Lanzone), se encontraban en depósitos en el mismo estado en que fueran traídos luego de las campañas realizadas en el área. Con estos últimos, una de nosotras junto a otros investigadores hemos realizado un rescate que permitió no solo inventariar cada uno de los materiales, sino también acondicionarlos y preservarlos para futuras investigaciones (Elías 2006).

A la hora de caracterizar contextualmente tanto al registro cerámico como al óseo procedente ya sea del sector de enterratorios o del sector habitacional, se recurrió a distintos tipos de fuentes. Cabe aclarar que en lo que respecta al registro de gran parte de la colección Doncellas, existen carencias que en muchos casos limitan determinado tipo de propósitos relacionados con las investigaciones, aunque coincidimos con la idea de que "la conservación de los fondos museográficos brinda la posibilidad de dar continuidad al conocimiento prehistórico a través del análisis de las colecciones depositadas en ellos", como así también "que las colecciones arqueológicas depositadas en museos.... proporcionan una fuente de información útil a la investigación" a partir de "...la cual es el investigador quien conjuga los materiales transformándolos en datos válidos" (Pérez de Micou 1998: 231).

Por lo tanto, para contextualizar y cuantificar a los materiales arqueológicos, se utilizaron los trabajos publicados de Alfaro de Lanzone (1983 y 1988) y Alfaro de Lanzone y Suetta (1976) y los inventarios del Museo Etnográfico de Buenos Aires de los años 1943, 1944 y 1945, que registran los materiales ingresados por Casanova procedentes de sus campañas a Doncellas y discriminados por enterratorios a los que él denomina Yacimientos.

\section{Cerámica}

Las muestras utilizadas para esta investigación proceden de dos contextos diferentes. Por un lado, aquellos materiales excavados por Alfaro de Lanzone que provienen 
del sector habitacional, los cuales se encuentran en el INAPL y cuya muestra esta compuesta por 947 fragmentos y 46 piezas completas. Por otro lado, los conjuntos cerámicos obtenidos por Casanova en el sector de enterratorios suman 29 piezas completas provenientes del IIT y más de 200 piezas, también completas, del ME. Hasta el momento, solo se había realizado una primera comparación entre las muestra teniendo en cuenta solo el material del IIT (Pérez 2009).

El tipo de análisis realizado a las colecciones comprendió la reconstrucción morfológica (en el caso que se tratara de fragmentos) y el análisis técno-estilístico y morfológico del conjunto cerámico. Con respecto a las técnicas, se recurrió a la estimación métrica, la observación macroscópica a ojo desnudo y con lupa binocular (1०X), el registro fotográfico y se utilizó un gráfico de bordes para la reconstrucción de las formas.

Si bien en trabajos previos se focalizó en las características tecnológicas de los conjuntos cerámicos (Pérez 2008), para esta investigación se consideraron principalmente los aspectos estilísticos y formales, teniendo en cuenta que este tipo de análisis permite la identificación de tradiciones culturales que derivan de la expresión pasiva de la identidad y a su vez cumplen la función de comunicarla (Jones 1997). En este sentido, las características morfo-estilísticas de los conjuntos cerámicos que circulan dentro de una comunidad no son azarosos sino el resultado de prácticas socialmente aprehendidas y transmitidas, que implican el conocimiento de un código compartido acerca de cómo las cosas deben hacerse (Rice 1987, Rye 1981, Basile 2009 en el Noroeste Argentino).

\section{Registro óseo humano}

Los materiales provienen de distintas partes del yacimiento arqueológico y comprenden una serie esqueletal que está constituida por esqueletos relativamente completos, restos mezclados (commingled remains) y huesos aislados (Buikstra y Ubelaker 1994). La misma está constituida por 627 especímenes óseos, los cuales fueron relevados utilizando las fichas proporcionadas por el Standards for Data Collection from Human Skeletal Remains (Buikstra y Ubelaker 1994). La selección de las piezas para el análisis tuvo como criterio evitar la pérdida de información de otras líneas de evidencia (por ejemplo, análisis paleopatológicos a cargo de Paula Miranda, com. pers.). Es por ello que no se realizaron análisis destructivos de aquellos individuos solo representados por sus cráneos.

Solo se han incluido en este trabajo los valores obtenidos de individuos asociados al sector Farallones y Poblado de la Localidad arqueológica, especificándose el caso de dos individuos que provisoriamente asociaremos al sector poblado, dado que la información contextual se ha perdido y la investigadora Alfaro de Lanzone no ha detallado otros sectores posibles de procedencia de restos humanos. Una salvedad merece el individuo representado por la muestra DON 138, el cual proviene de una excavación realizada en el sector de Farallones $\mathrm{N}$, es decir, aquel que se enfrenta al Farallón de donde proceden la mayoría de los conjuntos óseos que conforman las tres colecciones museológicas. Este individuo que se halló envuelto en poncho de lana de color marrón claro y sin acompañamiento mortuorio, posee un fechado asociado que lo ubica en la cronología de ca. 1310 DC (Alfaro de Lanzone 1988). En cambio, los individuos procedentes de Farallón $\mathrm{S}$ se hallaron juntos, con acompañamiento mortuorio y fueron asociados a un fechado que los ubica hacia ca. 1490 DC (Alfaro de Lanzone 1988).

Las piezas óseas a considerarse serán las costillas, pues contienen un alto porcentaje de tejido óseo cortical, presentan menos dificultades en la extracción de contaminantes húmicos y la pérdida de información osteológica con ellas es mínima (Ambrose 1993). Lamentablemente, no se encuentran representadas entre todos los individuos, debiendo efectuarse, en algunos casos, el procedimiento en fragmentos de cráneo y vértebra.

Metodología Isotópica. El análisis de isótopos estables, en especial del carbono $\left({ }^{13} \mathrm{C} /{ }^{12} \mathrm{C}\right)$ y nitrógeno $\left({ }^{15} \mathrm{~N} /{ }^{14} \mathrm{~N}\right)$, se estableció como evidencia independiente y confiable en el testeo de hipótesis en las problemáticas paloedietarias. Esto debido a que la señal isotópica de los elementos de los tejidos humanos deriva de los alimentos asimilados, además de mantenerse constante a pesar del deceso del individuo (Ambrose 1993). Cada alimento tiene un rango de distribución isotópico específico (expresada en $\delta \%$ ) (Shoeninger 1995) y existe un factor de fraccionamiento que 
implica un enriquecimiento isotópico entre el alimento y el tejido final (Ambrose 1993). Las relaciones de los isótopos estables utilizando la notación delta ${ }^{3}$ y con el símbolo $\Delta$ representan el enriquecimiento que ocurre entre los tejidos del consumidor y lo que es consumido. El análisis de $\delta^{13} \mathrm{C}$ permite distinguir diferentes fuentes de recursos, pues ingresa en la cadena trófica tras ser asimilado por los vegetales de manera diferencial (Ambrose 1993), ya que existen tres patrones fotosintéticos: $\mathrm{C}_{3}$ (especies arbóreas, arbustos y la mayoría de las plantas silvestres de la puna, con valores $\delta^{13} \mathrm{C}$ con un promedio de $-27 \%$ ), $\mathrm{C}_{4}$ (maíz, algunos amarantos, caña de azúcar y sorgo, con un promedio $-12,5 \%$ ) y las crasuláceas de metabolismo ácido (cactus y orquídeas, con valores semejantes a plantas con los otros dos patrones). Asimismo, este valor se transmite a otros niveles tróficos, lo que deja lugar a una estimación de los componentes dietarios (Tieszen 1991). Dado que el fraccionamiento es conocido (5\%o), el análisis del colágeno de un herbívoro podrá estimar el inicio de su cadena alimentaria (Squeo y Ehleringer 2004).

En lo que refiere al material óseo, el colágeno del hueso sigue un modelo de "enrutamiento", ya que es producto principalmente de la porción proteica de la dieta. En cambio, la apatita sintetiza carbohidratos, lípidos y proteínas no utilizadas en la síntesis de tejidos (Krueger y Sullivan 1984). Por lo tanto, se presenta un sesgo, relacionado con que algunos de los aminoácidos en el maíz contribuirían a la síntesis del colágeno, pero las proteínas animales siempre garantizarían la totalidad de los aminoácidos indispensables para ello; esto, dependiendo de las cantidades ingeridas.

En lo referente a las relaciones isotópicas de $\delta^{15} \mathrm{~N}$, estas permiten inferir la incidencia del consumo de proteínas vegetales y de animales terrestres y marinos. Por lo tanto, la arqueología y la ecología pueden utilizarlas para estimar la posición trófica del individuo, dado que el consumidor cuenta con un enriquecimiento típico del $3-4 \%$ en el ${ }^{15} \mathrm{~N}$ relativo a su dieta (De Niro y Epstein

$3 \mathrm{~d}^{13} \mathrm{C}$ representa la diferencia entre la medición de la relación isotópica que nos interesa y la relación isotópica de un estándar. Para el caso del carbono, es el carbonato V-Pee Dee Belemnite. Debido a que esta diferencia es muy pequeña, dicha relación es expresada como partes por mil (\%), siguiendo la siguiente ecuación: $\mathrm{d}^{13} \mathrm{C}=$ $\left[\left(\mathrm{T}_{\text {muestra/ }} / \mathrm{T}_{\text {estándar }}\right)-1\right] \mathrm{x} 1000$. Para el caso del nitrógeno ${ }^{15} \mathrm{~N}$ (\%) $=\left[\left({ }^{15} \mathrm{~N} /{ }^{14} \mathrm{~N}\right) \_\right.$muestra $-\left({ }^{15} \mathrm{~N} /{ }^{14} \mathrm{~N}\right) \_$estándar $/\left({ }^{15} \mathrm{~N} /{ }^{14} \mathrm{~N}\right) \_$estándar $]{ }^{*} 100 \mathrm{O}$.
1981). Ahora bien, las relaciones isotópicas pueden verse alteradas por razones independientes al fraccionamiento trófico. Por ejemplo, la disponibilidad de agua, considerando las precipitaciones anuales como indicador, ha sido señalada como una variable íntimamente relacionada con los valores obtenidos sobre el colágeno del hueso de herbívoros, registrándose una relación negativa entre ambos en diferentes continentes (Sealy et al. 1987, Cormie y Schwarcz 1996). Esta relación ha sido explicada por la presencia de un mayor contenido de nitrato y amonio en los suelos salinos, los cuales son característicos de los ambientes áridos (Pate 1994, Amundson et al. 2003, Austin y Vitousek 1998). Asimismo, se ha afirmado que entre herbívoros viviendo en ambientes áridos el enriquecimiento en $\delta^{15} \mathrm{~N}$ sería indicador de una adaptación fisiológica, ante una situación de estrés. Se debería a una capacidad de los animales de conservar agua, excretando orina con altas concentraciones de urea empobrecida en ${ }^{15} \mathrm{~N}$ (Sealy et al. 1987). Pero, por el momento, el apoyo a la explicación de la relación negativa entre los valores de nitrógeno sobre el colágeno en herbívoros y la disponibilidad de agua recae sobre el rol de los valores de $\delta^{15} \mathrm{~N}$ en las plantas antes que en causas metabólicas en los animales (Murphy y Bowman 2006). Otros factores de enriquecimiento son el uso de fertilizantes en los suelos, ya sean estos naturales como artificiales (Bogaard et al. 2007).

Todos estos elementos nos generan expectativas sobre los valores en nitrógeno en la Doncellas, dada la aridez típica de la puna y la probable importancia de prácticas de abono en sociedades agrícola pastoriles. En este sentido, es fundamental remarcar que se han encontrado valores enriquecidos de nitrógeno en camélidos de Susques, Puna de Jujuy (Yacobaccio et al. 2010) y también en la Quebrada de Humahuaca (Mengoni Goñalons 2007), lo cual nos advierte sobre la importancia de las relaciones isotópicas en la base de las cadenas tróficas y como influye esto en los sucesivos consumidores.

\section{* Resultados}

\section{Cerámica}

Análisis de la colección Alfaro de Lanzone (sector habitacional). Una vez realizado el análisis morfo-estilístico a los ma- 


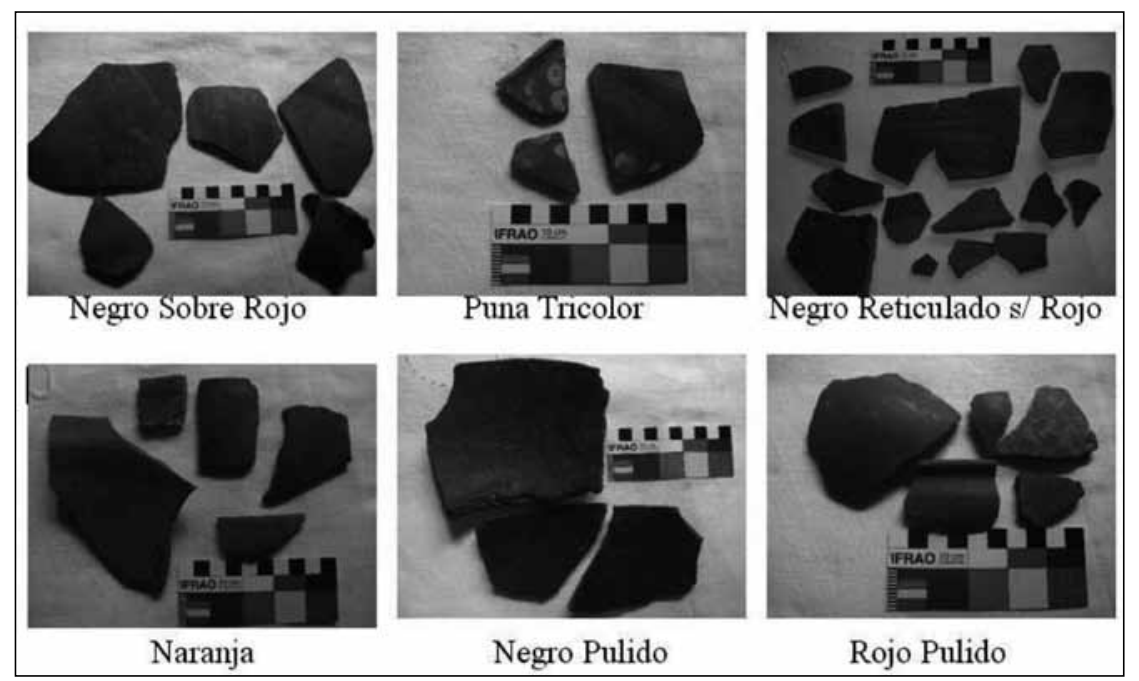

Figura 4. Grupos tipológicos en la Colección Alfaro de Lanzone INAPL (sector habitacional).

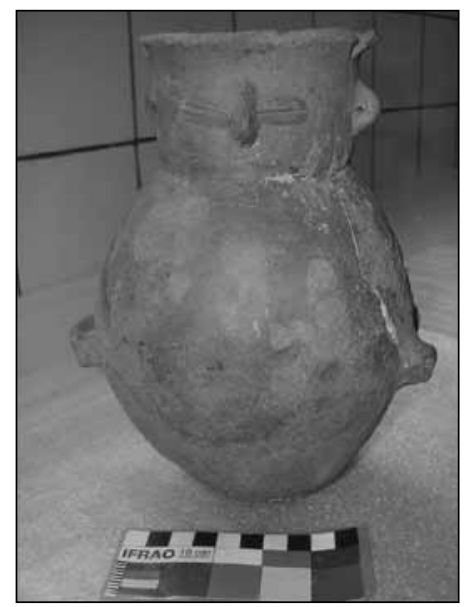

Figura 5. Urna Puna Tricolor Colección Alfaro INAPL.

teriales provenientes del sector habitacional, fue posible identificar los siguientes grupos tipológicos (Figura 4).

1. Negro sobre rojo: el negro se presenta en motivos geométricos con líneas de contorno grueso, a veces formando una $\mathrm{V}$, sobre el rojo de base. Este tipo generalmente está representado en pastas de textura mediana gruesas, de atmósfera oxidante con inclusiones de tamaño mediano. Su presencia es muy alta en el total de la muestra.

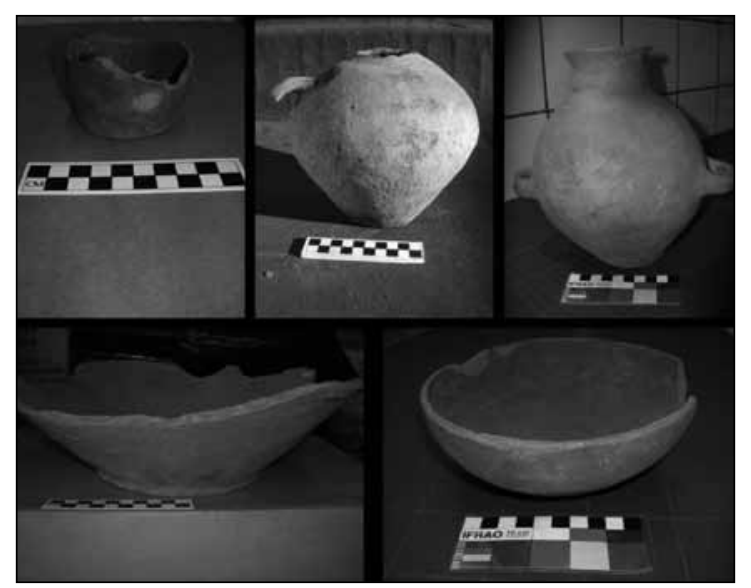

Figura 6. Cerámica no decorada: base, cántaro, fuente y escudilla. Colección Alfaro INAPL.

2. Negro reticulado sobre rojo: el negro se presenta en líneas negras reticuladas, que en algunos casos rellenan formas geométricas, sobre rojo pulido o simplemente alisado. Las pastas son de textura fina a mediana de atmósfera oxidante con inclusiones de tamaño fino y mediano. La superficie interna y la externa están pulidas en la mayoría de los casos.

3. Rojo Pulido: presenta pintura roja, desde tonalidades amarronadas hasta anaranjadas, que en algunos ca- 


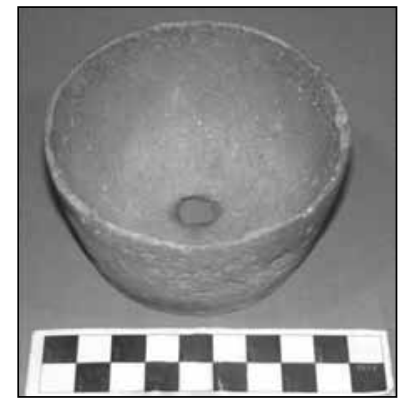

Figura 7. Ejemplo de vasito chato. Colección Casanova ME "Juan B. Ambrosetti" (FFyL, UBA) N 44-1106.

sos es externa, en otros interna, o también en ambas superficies. La pasta es de textura fina, mediana o raramente gruesa, de atmósfera oxidante con inclusiones de tamaños muy variados, aunque predominan los tamaños finos. Generalmente, están pulidas en las caras externas y muy alisadas en la interna.

4. Puna Tricolor: esta denominación es la que Alfaro de Lanzone le da a ese tipo particular de cerámica, posterior a que Krapovickas (1958-1959) presentara un tipo con las mismas características al cual denominó Queta Tricolor y al que Albeck y Ruiz (2003) denominan Casabindo, considerando este estilo como representante típico de la Cuenca Miraflores-Guayatayoc. Los motivos son similares al grupo negro sobre rojo pero en este caso se agregan lunares de pintura blanca, que se realizaron en todos los casos luego de la cocción de las piezas (algunas veces también se presentan en negro). Muchas de estas piezas poseen un modelado antropomorfo en la sección del cuello cuyos ojos y nariz han sido aplicadas por pastillaje siendo los primeros en forma de granos de café. Las pastas son de atmósfera oxidante de textura mediana a gruesa (Figura 5).

5. Negro Pulido: presenta pintura negra pulida en la superficie interna y a veces también en la externa. La pasta generalmente es de textura fina, con predominancia de atmósfera reductora, con mucho material orgánico en su composición. Las inclusiones son fini-medianas y es abundante la mica en la mayoría de los casos.

6. Naranja: la pintura es de tonalidades ocres a naranja y generalmente se presenta en la cara externa. Las tex- turas son en su mayoría finas, de atmósfera oxidante con inclusiones muy finas. Generalmente, alguna de las superficies, o ambas, se encuentran pulidas. Se encuentra mínimanente representado.

7. Cerámica no decorada: en este grupo las pastas son de textura mediana a gruesa y la atmósfera de cocción predominante es la de tipo oxidante, en algunos casos incompleta, con presencia de algunas reductoras. Muchos fragmentos presentan posibles depósitos de lípidos y solo un bajo porcentaje presenta restos de hollín. Es importante destacar que este tipo de cerámica no decorada en la mayoría de los casos es de muy buena terminación, presentando una muy buena calidad de alisado tanto en la cara externa como en la interna (Figura 6). Entre las variedades formales se encuentran representadas diferentes tipos, casi en su mayoría aquellas relacionadas con aspectos del servicio de comidas (escudillas, ollas, fuentes, jarras, vasos, etc.).

Un párrafo aparte merecen los vasitos chatos ya que los mismos suman un total de 69 objetos encontrados. Estos vasitos son también conocidos con el nombre de vasitos hilanderos ya que muchos de ellos se han encontrado con un agujero en el centro, el cual se piensa pudo servir para sostener el uso al hilar. En nuestra muestra, se han hallado algunos con esta característica tan peculiar (Figura 7).

El análisis morfológico de los fragmentos permitió identificar las siguientes categorías formales:

1. Vasijas no restringidas de contornos simples: pucos, escudillas, platos, vasos y fuentes. Los pucos, escudillas y platos se presentan en la mayoría de los casos sin decoración y con paredes de grosores medianos (entre 6 y 9 $\mathrm{mm}$ ). Los vasos son del tipo vasitos chatos o puneños de cerámica no decorada, con muy buena calidad en su terminación, cuya altura oscila entre 6 y $10 \mathrm{~cm}$ con diámetros de $11 \mathrm{~cm}$ promedio y paredes finas (menores a 6 $\mathrm{mm}$ ). En el caso de las fuentes, las mismas no presentan decoración, poseen paredes muy gruesas (mayores a $10 \mathrm{~mm}$ ) y los tamaños generalmente son de medianos a grandes (diámetro superior a $20 \mathrm{~cm}$ ).

2. Vasijas restringidas simples y dependientes: pucos, escudillas, ollas y cántaros. Los pucos y escudillas presentan grosores medianos y en su mayoría no 


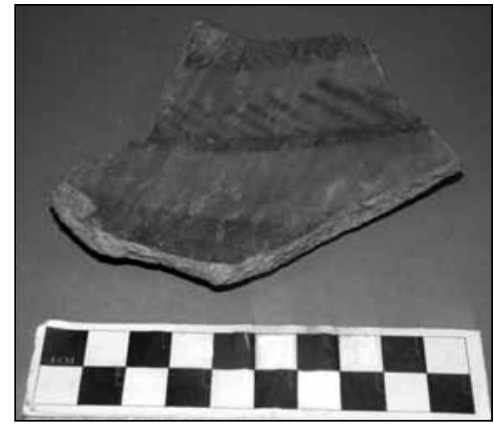

Figura 8. Ejemplo atípico del grupo Negro reticulado sobre Rojo. Colección Casanova ME “Juan B. Ambrosetti” (FFyL, UBA) n ${ }^{\circ}$ 43-1796.

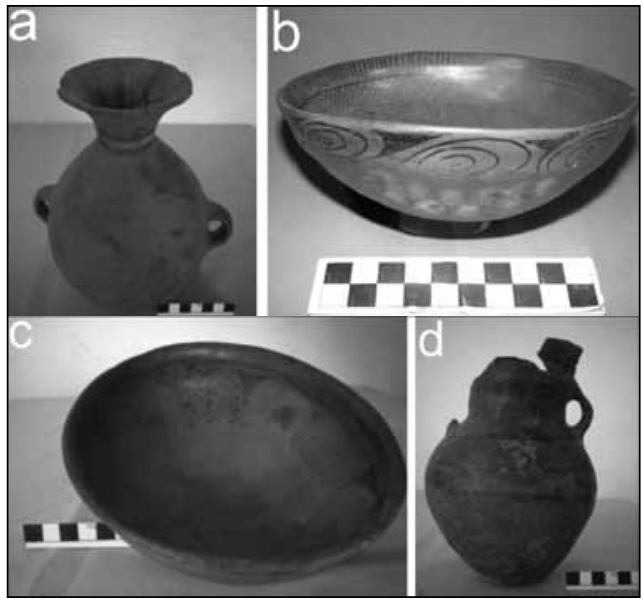

Figura 9. Recipientes cerámicos del grupo Yavi. Colección Casanova IIT y ME “Juan B. Ambrosetti” (FFyL, UBA), a: 43-1130, b: 43-144, c: 43-1126 y d: 42-2080.

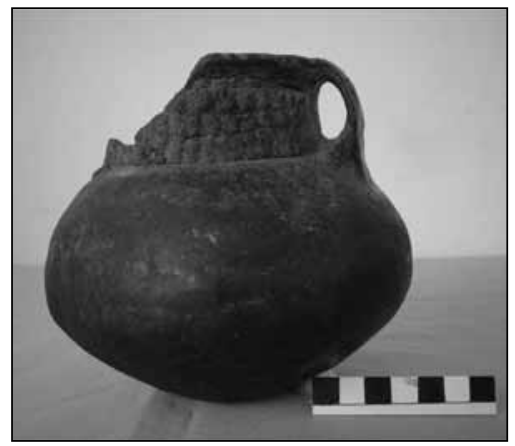

Figura 10. Cerámica con características del área de yungas. Colección Alfaro INAPL. están decorados. Las ollas son de cerámica no decorada, con paredes mediano-gruesas y los diámetros varían entre 10 y $30 \mathrm{~cm}$. En este tipo de formas, es posible observar manchas de cocción en las superficies externas y manchas de lípidos en las internas.

3. Vasijas restringidas independientes: urnas, jarras, cántaros y ollas. Entre las urnas se observan algunas sin decoración y otras del grupo tipológico Puna tricolor. Entre las del primer grupo, algunas se encontraban asociadas a párvulos y ajuar funerario. Las jarras y cántaros son de cerámica no decorada, las paredes son de grosores medianos, el orificio de salida tiene un diámetro que oscila entre los $5 \mathrm{y} 7 \mathrm{~cm}$ y poseen una altura promedio de $22 \mathrm{~cm}$.

Análisis de la Colección Casanova (tumbas). Tanto el material cerámico del IIT como el del Museo Etnográfico de Buenos Aires corresponde, casi en su totalidad, a piezas completas y el análisis morfo-estilístico de las mismas posibilitó identificar los siguientes grupos tipológicos:

1. Cerámica no decorada: el conjunto de estas piezas se corresponde con las formas ya descriptas para la primera muestra: vasitos chatos, escudillas, ollas, fuentes, cántaros o jarras y jarritas más pequeñas.

2. Negro reticulado sobre rojo: este estilo decorativo se presentó en pocas piezas completas y en fragmentos pertenecientes a la colección del Museo Etnográfico. Entre éstos, aparecieron muy representados fragmentos con esta misma variedad cromática pero en los trazos del negro figuran una nervadura de pluma a la cual le falta una de sus mitades. Esto no se había registrado en la colección Alfaro y podría corresponderse con un nuevo grupo estilístico (Figura 8).

3. Rojo Pulido: se encuentra representado en escudillas y en vasijas subglobulares de medianas dimensiones.

4. Puna tricolor: los recipientes que presentan este estilo decorativo pertenecen a solo dos vasijas de gran tamaño (más de un metro de alto y más de $30 \mathrm{~cm}$ de diámetro), las cuales por sus características formales y dimensionales se podrían vincular con la función de almacenaje de alimentos ya sea líquidos (como chicha) o sólidos. Cabe aclarar que, si bien corresponden a la 


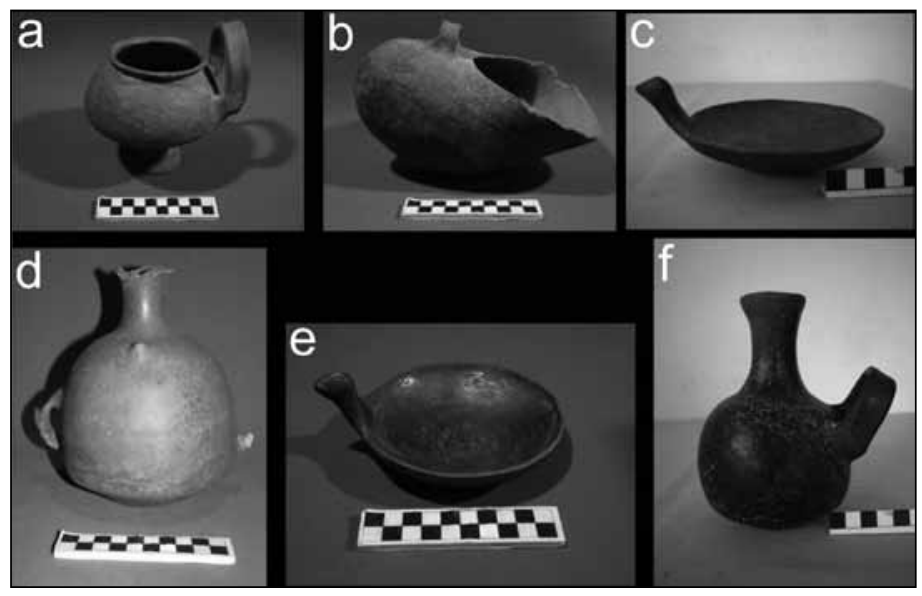

Figura 11. Recipientes del tipo incaico. Colección IIT y ME “Juan B. Ambrosetti” (FFyL, UBA). a: 43-130, b: 43-1142, c: 43-1129, d: 43-1134, e: 43-1128 y f: 43-1131.

colección del IIT, los mismos no provienen del área de tumbas, por lo que no se encontrarían representados en este sector.

5. Yavi: hay algunos recipientes que presentan características propias del estilo yavi como las combinaciones pautadas de color, la morfología y las segmentaciones pictográficas (ver Ávila 2008). Ejemplos de este estilo y pertenecientes a la colección del IIT son los casos de un tipo de cazuela cuya decoración se presenta en motivos reticulados y triangulares en negro sobre ante (Ávila op. cit.) y un tipo de vasija subglobular con decoración en banda discontinua con motivos geométricos de fino reticulado en negro sobre naranja (Ávila op. cit.) (Figura 9 d). También se adscribe a este estilo otro tipo de vasija subglobular que posee un cuello subcilíndrico y borde evertido con decoración de líneas paralelas marrones en el cuello y blanca con reborde alrededor del mismo (Ávila op. cit.) (Figura 9 a) y una escudilla no restringida que presenta una decoración interior dividida en cuatro sectores con motivos ornitomorfos los cuales se encuentran separados por bandas en cruz de motivos geométricos en zigzag, en cuya superficie externa se puede observar una banda continua de motivos triangulares con apéndices espiralados en negro sobre rojo con un borde de motivos de triángulos espiralados y fino reticulado (Ávila op. cit.) (Figura 9 c). En la colección del Museo Etnográfico, se registraron una escudilla de fina terminación y características muy similares a la última descripta (Figura 9 b) y distintos tipos de vasijas de medianos tamaños con características más burdas que el caso anterior, pero que mantienen los criterios estilísticos citados anteriormente (Figura 9).

6. Negro s/ marrón: también se registró este tipo de vasija subglobular similar a las pequeñas urnas del tipo Puna tricolor (mencionadas por Alfaro de Lanzone), pero en este caso con decoración geométrica negra sobre marrón.

7. Cerámica con características del área de yungas: en la colección Casanova, se presentó un tipo de vasija geoidal negro pulida de cuello cilíndrico corrugado con características que la podrían vincular con la zona de yungas y también fragmentos sin pintura con decoración incisa y corrugada particular de este tipo de estilos (Figura 10).

8. Inca: desde el punto de vista morfológico, se registró la presencia de diez platos de base plana, con modelado ornitomorfo del tipo plato pato incaico y cuatro del tipo aribaloide. Además, se registraron fragmentos de cerámica con características incaicas y dos formas netamente incaicas (Iriarte com. pers.), como la ollita roja pulida con base pedestal y asa lateral acintada y el recipiente para contener líquidos que se muestra en la imagen de la Figura 11. 


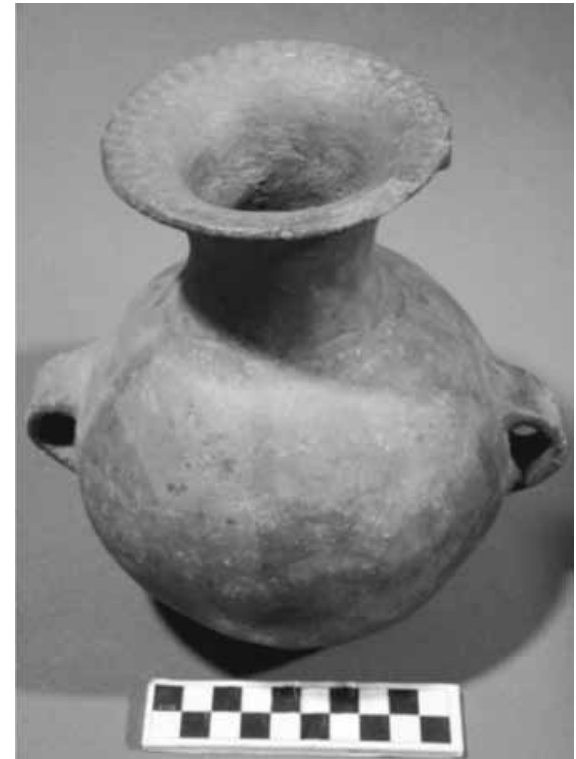

Figura 12. Recipiente del tipo Humahuaca-Inka. Colección ME "Juan B. Ambrosetti" (FFyL, UBA) N 43-1131.

9. Negro Pulido: esta variedad estilística se registró en escudillas de tamaños medianos provenientes de la colección del ME.

10. Humahuaca-Inka: fue registrado en la colección del $\mathrm{ME}$, en una pieza completa con motivos de banderines negros sobre rojo y en algunos fragmentos (Figura 12).

Aspectos funcionales. El análisis de los conjuntos cerámicos procedentes de los dos sectores mencionados no solo evidenció una diferencia respecto a los grupos estilísticos recurrentes en cada uno de ellos, sino que también manifestó una diferencia de tipo funcional en el conjunto de los recipientes pertenecientes a cada una de las muestras.

En las muestras procedentes del sector habitacional, fue posible identificar un alto porcentaje de cerámica con formas asociadas a funciones domésticas, como la cocción y el servicio de alimentos (vasos, jarras, fuentes, escudillas, etc), siendo elevado el número de ollas que en muchos casos presentaron manchas de hollín en su superficie externa. Los estilos decorativos que predominan son aquellos característicos del complejo de la Puna de Bennet (Bennet et al. 1948) como el Negro s/ Rojo, el Rojo Pulido, los vasitos chatos y el Puna Tricolor o Casabindo (Tabla 2).
En el caso de la muestra procedente del sector de sepulcros, si bien se han registrado recipientes relacionados con el servicio de comida, como por ejemplo las escudillas, muchos de ellos se encuentran finamente decorados y a nivel macroscópico no presentan huellas de uso relacionadas con la alimentación. Esto permitiría relacionarlos con prácticas de tipo ritual, sumado a que a su vez es en esta muestra donde se detectan, en mayor proporción, los estilos decorativos foráneos relacionados con el Imperio inkaico, con las yungas, con la Cultura Yavi y con la quebrada de Humahuaca, entre otros todavía no definidos (Tabla 3). Un párrafo aparte merecen los vasos chatos cuya alta proporción se vincula con la actividad textil y que se retomará en la discusión del trabajo.

\section{Isótopos estables e interpretación paleodietaria}

Los valores de $\delta^{13} \mathrm{Ccol}$ (Tabla 4), utilizando como criterio la relación $\mathrm{C} / \mathrm{N}$, son confiables para todas las muestra, dado que el promedio es de 3,3 $\pm 0,4$, con excepción de DON 331. Sin embargo, si consideramos los porcentajes de pesos de colágeno obtenido sobre esta fracción, la totalidad de las muestras responden favorablemente al criterio de ser mayor al 1\% (Van Klinken 1999), así como también, poseen coherencia al interior del conjunto muestreado. Con respecto a los valores de $\delta^{13}$ Cap, poseemos una coherencia interna de los valores. En cuanto a los rendimientos obtenidos, el primer pesaje resulta satisfactorio para el criterio de Garvie-Lok y autores (2004) salvo para las muestras DON 88 y DON 353-68 (con una pérdida de 32,6\% y 40,4\%, respectivamente). En cambio, en el segundo pesaje solo, la segunda muestra no cumple con el porcentaje de pérdida esperado (Ambrose et al. 1997). En suma, se considerarán para este trabajo la totalidad de las muestras, aunque se tendrá en consideración este último valor como primario.

A continuación analizaremos los datos para una interpretación paleodietaria que discrimine el componente proteico y no proteico de la dieta total. Con respecto a los valores $\delta^{13} \mathrm{Ccol}$, exceptuando los individuos DON 35368 y DON 138, que poseen los valores $\delta^{13} \mathrm{C}-17,58 \%$ y $-17,54 \%$ respectivamente, se ajustan a los consumidores que poseen una dieta mixta, entre $-17 \%$ y -14\%o, según la categorización de Coltrain y Leavitt (2002). Es decir, que en su dieta se registra un consumo bajo o indirecto de $\mathrm{C}_{4}$. Este patrón concuerda con los valores para la 
Doncellas (Puna Septentrional, Jujuy, Argentina): Nuevos enfoques a partir del estudio cerámico...

\begin{tabular}{|l|c|c|c|}
\hline Formas & \multicolumn{2}{|c|}{ Poblado } & Enterratorios \\
\hline & Piezas completas & Fragmentos & Piezas completas \\
\hline Vasito & 7 & 5 & 69 \\
\hline Escudilla & 9 & 26 & 22 \\
\hline Cántaros dec. & 2 & 0 & 6 \\
\hline Aribaloide & 0 & 0 & 4 \\
\hline Plato pato & 0 & 0 & 6 \\
\hline Urna & 2 & 12 & 18 \\
\hline Jarra & 4 & 2 & 4 \\
\hline Fuente & 3 & 8 & 0 \\
\hline Olla & 8 & 61 & $\mathbf{2}$ \\
\hline
\end{tabular}

\begin{tabular}{|l|c|c|}
\hline Grupo estilístico & Poblado & Enterratorios \\
\hline Negro sobre Rojo & $33 \%$ & $12 \%$ \\
\hline Negro Reticulado s/ Rojo & $9 \%$ & $8 \%$ \\
\hline Negro pulido & $15 \%$ & $9 \%$ \\
\hline Puna Tricolor & $6 \%$ & $2 \%$ \\
\hline Rojo & $\mathbf{2 7} \%$ & $9 \%$ \\
\hline Chicha & $5 \%$ & $\mathbf{1 8} \%$ \\
\hline Inka & $\mathbf{0} \%$ & $32 \%$ \\
\hline Yungas & $\mathbf{0} \%$ & $4 \%$ \\
\hline Humahuaca-Inka & $\mathbf{0} \%$ & $2 \%$ \\
\hline Indefinido & $5 \%$ & $4 \%$ \\
\hline
\end{tabular}

Tabla 2. Variedades formales.

Tabla 3. Variedades estilísticas.

\begin{tabular}{|c|c|c|c|c|c|c|c|c|c|c|c|c|c|c|}
\hline 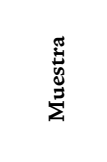 & $\begin{array}{l}\overline{\mathscr{U}} \\
\stackrel{m}{0}\end{array}$ & స్ల్లీ & 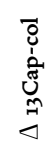 & 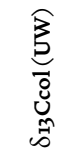 & 营 & ${ }_{u}^{z}$ & 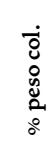 & 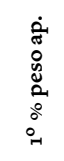 & 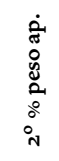 & 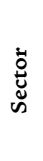 & 芉 & 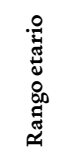 & 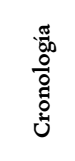 & 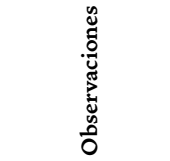 \\
\hline Don 88 & $-15,0$ & $-11,8$ & 3,6 & $-15,42$ & 12,47 & 3,18 & 22,1 & 67,4 & 47,6 & F & F & a & $\begin{array}{c}360 \pm \\
50\end{array}$ & $\begin{array}{l}\text { Acompa- } \\
\text { ñamiento } \\
\text { mortuório }\end{array}$ \\
\hline Don 138 & $-17,2$ & $-13,7$ & 3,8 & $-17,54$ & 11,86 & 3,17 & 23,9 & 80,7 & 69,3 & F & I & a & $\begin{array}{l}640 \pm \\
50\end{array}$ & $\begin{array}{c}\text { Envuelto en } \\
\text { poncho, sin ajuar }\end{array}$ \\
\hline Don 180 & $-15,8$ & $-12,2$ & 3,6 & $-15,82$ & 12,32 & 3,21 & 6,1 & 74,1 & 53,7 & P & I & I & S/D & $\mathrm{S} / \mathrm{D}$ \\
\hline Don 215 & $-14,6$ & $-12,5$ & 1,7 & $-14,24$ & 13,50 & 3,15 & 55,9 & 78,6 & 61,3 & F & M & a & $\begin{array}{c}360 \pm \\
50\end{array}$ & $\begin{array}{l}\text { Acompa- } \\
\text { ñamiento } \\
\text { mortuório }\end{array}$ \\
\hline Don 224 & $-14,8$ & $-13,1$ & 1,2 & $-14,32$ & 11,81 & 3,17 & 22 & 77,2 & 59,3 & F & F & a & $\begin{array}{c}360 \pm \\
50\end{array}$ & $\begin{array}{l}\text { Acompa- } \\
\text { ñamiento } \\
\text { mortuório }\end{array}$ \\
\hline Don 331 & $-16,3$ & $-13,0$ & 4,0 & $-17,00$ & 15,00 & 4,11 & 4,4 & 80,8 & 64,8 & P & I & I & S/D & $\begin{array}{l}\text { Orificio en } \\
\text { occipital }\end{array}$ \\
\hline $\begin{array}{l}\text { Don } 353^{-} \\
\quad 68\end{array}$ & $-17,3$ & $-12,4$ & 5,2 & $-17,58$ & 17,57 & 3,15 & 15 & 59,5 & 35,3 & $\mathrm{P}$ & I & suba. & $S / D$ & En urna tosca \\
\hline Don 385 & $\mathrm{~S} / \mathrm{D}$ & $-12,9$ & 2,6 & $-15,51$ & 14,46 & S/D & 2,3 & 78,7 & 66,3 & P & F? & j & $\mathrm{S} / \mathrm{D}$ & S/D \\
\hline Media & $-15,9$ & $-12,7$ & 3,2 & $-15,9$ & 13,62 & 3,3 & 19 & 74,6 & 57 & & & & & \\
\hline $\begin{array}{c}\text { desviación } \\
\text { estandar }\end{array}$ & 1,12 & 0,60 & 1,29 & 1,33 & 1,98 & 0,4 & 17 & 7,51 & 11 & & & & & \\
\hline
\end{tabular}

Tabla 4. Información de isótopos estables sobre muestras de restos humanos de la Localidad Arqueológica Río Doncellas.

$\mathrm{F}=$ Farallones, $\mathrm{A} / \mathrm{C}=$ Alero/Cueva, $\mathrm{P}=$ Poblado y $\mathrm{C}=$ Cueva. 


\section{Ecología isotópica - valores $\delta^{13} \mathrm{C}_{\mathrm{col}}$}

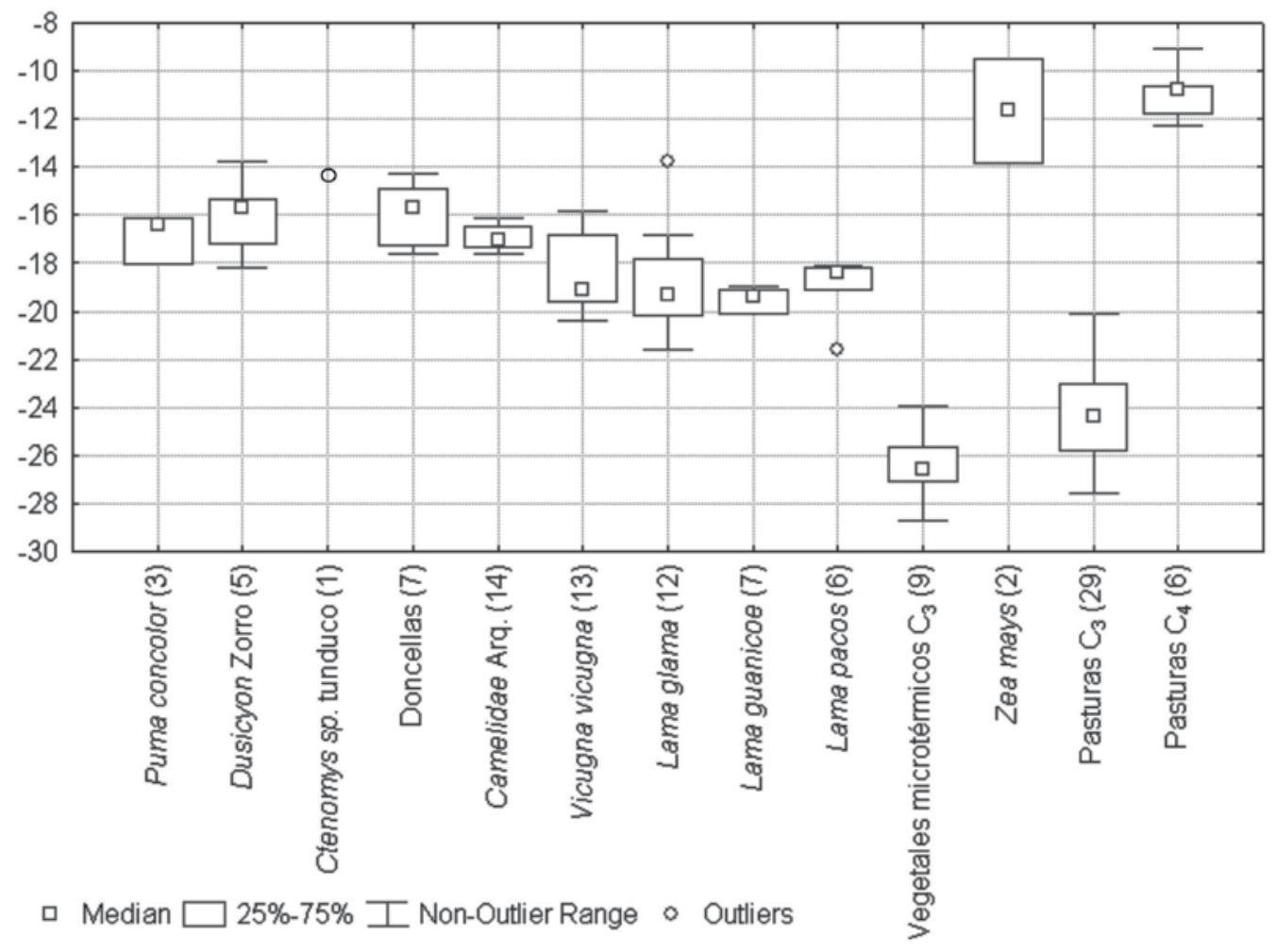

Figura 13. Box plots con valores disponibles de $\delta^{13} \mathrm{C}_{\mathrm{col}}$ de animales de la puna septentrional oriental. Nótese la ubicación de Ctenomys y la posición atípica de Lama Glama, explicados en Fernández y Panarello (1999-2001a) por el consumo de pasturas altoandinas $\mathrm{C}_{4}$. El fraccionamiento de las muestras humanas se ubica en el $4 \%$ con respecto a Lama glama.

ecología isotópica obtenidos en el área bajo estudio, los cuales se sintetizan en la Figura 13. En este sentido, es fundamental destacar que los herbívoros del área tienen acceso a pasturas $\mathrm{C}_{4}$ en los campos llanos y húmedos denominados llamerías. Estos lugares de explotación pastoril se encuentran, por ejemplo, al sur de Puesto del Marqués y Abra Pampa. Por lo tanto, deben tenerse en cuenta los valores obtenidos en estudios actuales sobre camélidos que en alturas menores a los 4000 m.s.n.m. infieren una mayor inclusión de especies $\mathrm{C}_{4}$, siendo los valores promedio en vicuña $-16,8 \%$ y en llama $-17,3 \%$ (Fernández y Panarello 1999-2001b, Samec 2011).

En lo que respecta a datos de camélidos provenientes de contextos arqueológicos, contamos con el análisis de un montículo en Pozuelos, área próxima a la localidad arqueológica bajo análisis en este trabajo. El conjunto consta de un promedio de $\delta^{13} \mathrm{C}-16,5 \%$ para camélidos durante un intervalo cronológico que se extiende desde 455 hasta 745 años AP (Fernández y Panarello 19992001a). Asimismo, los datos disponibles para quínoa, papa y oca de valores obtenidos en el noroeste argentino se encuentran dentro del patrón fotosintético $\mathrm{C}_{3}$. Si observamos la Figura 13, el rango de dispersión de los valores disponibles los posiciona incluso más empobrecidos respecto a las pasturas $\mathrm{C}_{3}$ en la relación $\delta^{13} \mathrm{C}$.

Con respecto a los valores de $\delta^{13} \mathrm{Cap}$, estos no parecen evidenciar que en el análisis del colágeno existiera una subestimación de los macronutrientes no proteicos, pro- 


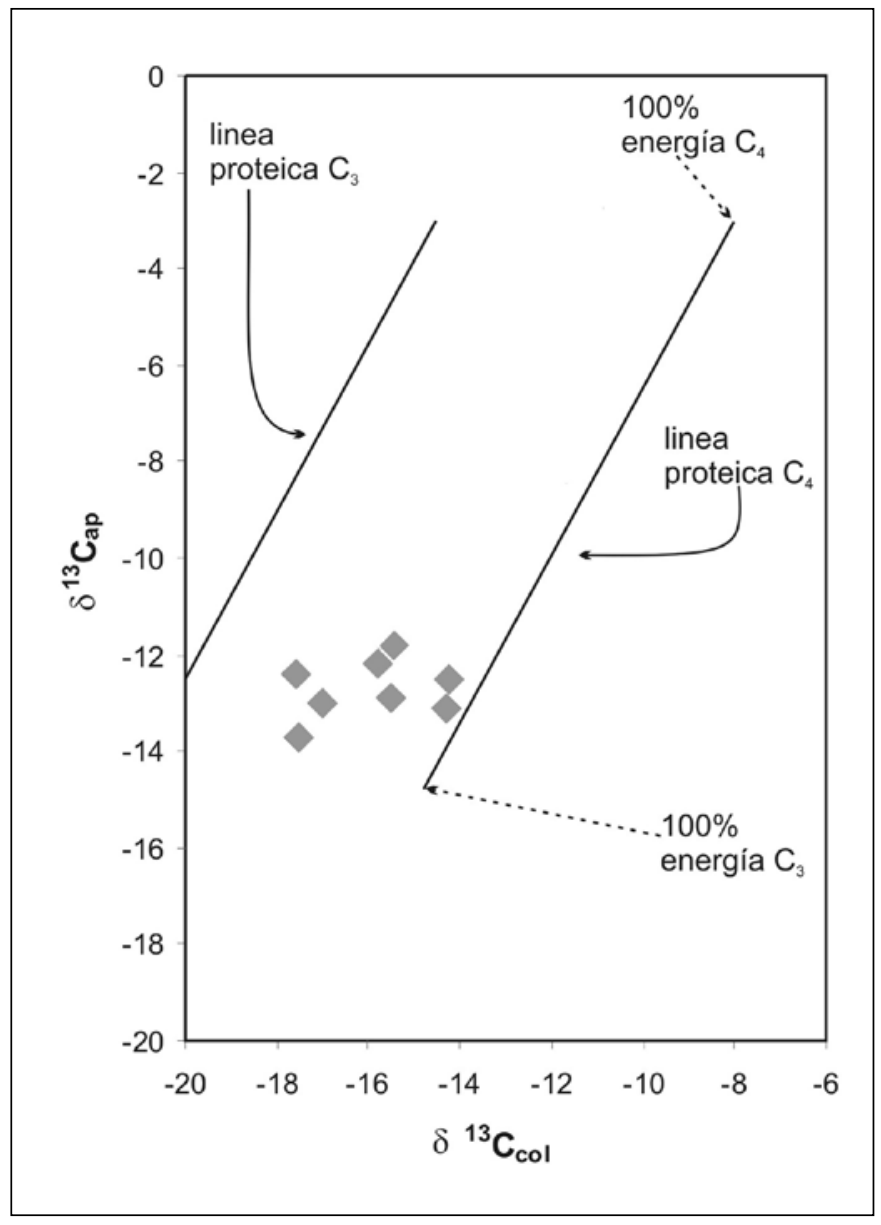

Figura 14. Valores $\delta^{13} \mathrm{C}$ en la fracción colágeno y apatita de los individuos analizados en Doncellas y comparados con las dos líneas de regresión del modelo de Kellner y Schoeninger (2007).

duciéndose un sesgo contra la asimilación de maíz. Los valores siguen estando empobrecidos si consideramos el fraccionamiento de $\sim 9,4 \%$ para $\Delta{ }^{13}$ Cap-dieta, pero iremos en mayor profundidad en esta línea de análisis. Ambrose y colaboradores (1997) sugieren que mientras la relación $\delta^{13}$ Cap-dieta sería siempre 9,4\%o dado que la fracción mineral del hueso sigue un modelo lineal, el valor $\delta^{{ }^{13}} \mathrm{Ccol}$-dieta sería igual a $5 \%$ solo si el valor $\delta^{13} \mathrm{C}$ de la porción proteica de la dieta y del resto de la dieta es el mismo, debido al modelo de "enrutamiento" que sigue el colágeno. Por lo tanto, el valor en $\delta^{13} \mathrm{Cap}$-col $4,4 \%$ solo es esperable si los valores $\delta^{13} \mathrm{C}$ de la porción proteica de la dieta son iguales al resto del total. En el caso de las muestras de Doncellas, solo el caso del subadulto (DON 353-68) supera este número, siendo todos los demás inferiores (con un promedio de 3,3). Entonces, solo en el caso señalado y teniendo en consideración que el rendimiento mineral no fue satisfactorio, el valor $\delta^{{ }^{13}} \mathrm{C}$ de la proteína en la dieta sería más negativo que el resto de los componentes. Por lo tanto, se trata de dietas con proteínas animales más enriquecidas que el resto de los macronutrientes.

Para analizar este aspecto recurriremos al modelo de Kellner y Shoeninger (2007), con implicancias en el comportamiento de los valores $\delta^{13} \mathrm{Ccol}$ en relación a los de $\delta^{13} \mathrm{Cap}$ (Figura 14). Las autoras proponen, basándose en estudios de dieta controlada, tres líneas de regresión para estimar el patrón fotosintético dominante en la composición proteica y energética de la dieta. Los valores de Doncellas, ubicados entre el extremo inferior de las líneas 


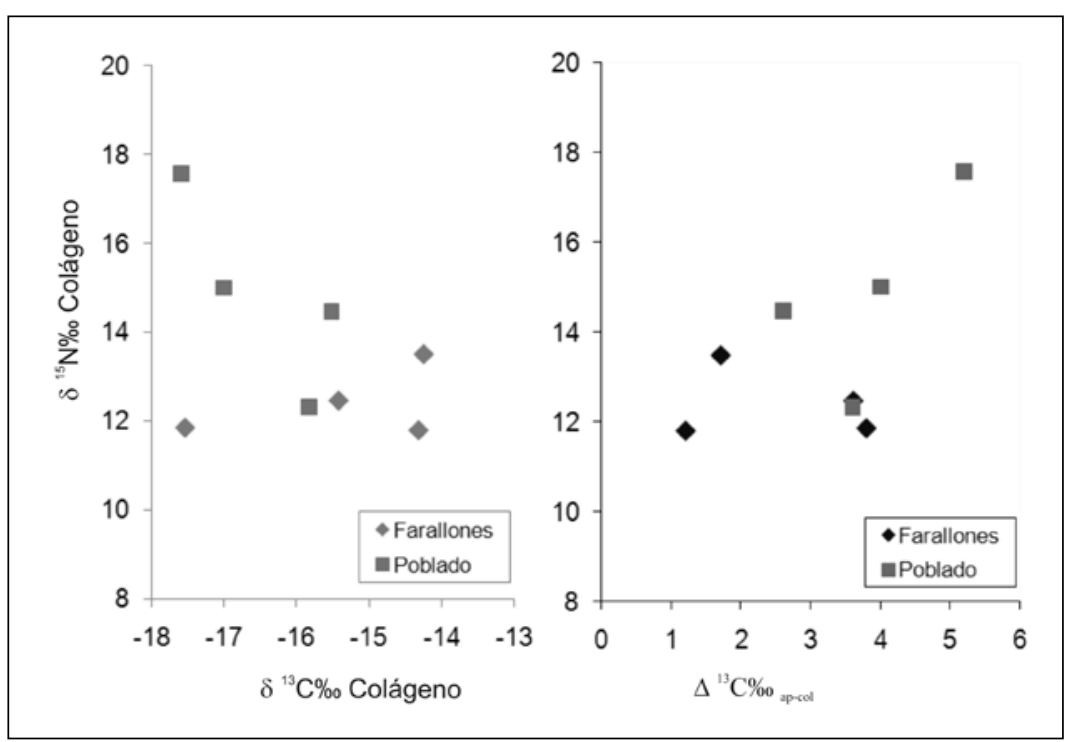

Figura 15. En el gráfico de la izquierda se presentan los valores isotópicos del carbono y el nitrógeno en la fracción colágeno del hueso para los individuos de los sectores Farallones (sepulcros) y Poblado. En el de la derecha los valores de la diferencia isotópica del carbón en la fracción apatita y colágeno y los valores isotópicos del nitrógeno.

proteicas $\mathrm{C}_{3}$ y $\mathrm{C}_{4}$, siempre se inclinan hacia un componente energético (carbohidratos y lípidos) con un patrón fotosintético $\mathrm{C}_{3}$. Aquellos valores, que se acercan a la línea proteica $\mathrm{C}_{3}$ podrían estar evidenciando el acceso a carne obtenida en altura, es decir aquellos herbívoros que pastan sobre los 3900 m.s.n.m. y que poseen una menor inclusión de pasturas $\mathrm{C}_{4}$ en su repertorio alimentario. En este sentido, los dos individuos masculinos hallados en Farallones $\mathrm{S}$ que poseen los valores más enriquecidos en $\delta^{13} \mathrm{Ccol}$ podrían asociarse al consumo de especies pastando en vegas de altura, como es el caso de las vicuñas, asociadas a las pasturas $\mathrm{C}_{4}$ por tener que estar obligadas a tomar agua, a diferencia de las llamas. Llamativamente, el individuo femenino proveniente de ese sepulcro, el cual no posee acompañamiento asociado a la hilandería, aunque sí marlos de maíz, es el que posee menor enriquecimiento en carbono respecto a los otros dos, pero sí tiene mayor enriquecimiento en la fracción apatita con respecto a todas las muestras. Es decir, posee una inclusión mayor, aunque modesta, de vegetales con patrón $\mathrm{C}_{4}$ o CAM. Insistimos en que esto ocurre en un contexto del consumo casi exclusivo de energía $\mathrm{C}_{3}$.

Con respecto a los valores de $\delta^{15} \mathrm{~N}$, la totalidad de los valores pueden asociarse a dietas con un alto aporte cár- nico, aunque tres individuos del poblado presentan los valores más enriquecidos (Figura 15). De todos modos, debemos tener presente que contamos con un subadulto. Dado que el amamantamiento de las crías de mamíferos hace que consuman una dieta un nivel trófico más alto que las dietas adultas, con un correspondiente enriquecimiento en $\delta^{15} \mathrm{~N}$ (Bocherens 2000), es esperable que un valor en nitrógeno tan enriquecido se deba a la condición de lactante del individuo, sumado a su emplazamiento dentro de cadenas tróficas que se encuentran enriquecidas a partir de su base. Debemos destacar que este valor se aparta de aquellos reportados en diversos estudios isotópicos humanos en Argentina.

\section{$*$ Discusión}

Las distintas líneas de evidencias utilizadas en este trabajo han dado a conocer diferencias cualitativas en los dos sectores discriminados del área arqueológica.

Desde el punto de vista material, el sector del poblado se encuentra asociado a un alto porcentaje de cerámica no decorada relacionado básicamente con funciones domésticas (cocción y servicio de alimentos). A su vez, los 
grupos estilísticos representativos de este sector del yacimiento son los característicos del complejo de la Puna de Bennet (Negro s/ Rojo, Rojo Pulido, vasitos puneños, Casabindo, etc.).

Desde el punto de vista paleodietario, en Doncellas, el análisis de $\delta^{13} \mathrm{C}$ en ambas fracciones del hueso no ha mostrado un grupo del todo homogéneo en cuanto a sus rangos de dispersión. Este hecho podría ser resultado de la naturaleza de la muestra, pues los individuos no proceden de un mismo sector ni tampoco de un mismo segmento cronológico, a lo que se suma que cuentan con contextos mortuorios diferentes.

Por otra parte, el sector de sepulcros presenta una alta recurrencia de materiales cerámicos finamente decorados, muchos de ellos sin presencia de huellas de un uso relacionado con la alimentación. En lo que se refiere a las características estilísticas, se encuentran presentes estilos decorativos foráneos relacionados con el Imperio inkaico, con las yungas, con la Cultura Yavi y con la quebrada de Humahuaca, entre otros aún no definidos.

Con respecto al registro isotópico, en el sector de sepulcros, los individuos de Hallazgo 3 (DON 88, DON 215 y DON 24), que poseen valores $\delta^{13} \mathrm{Ccol}$ más enriquecidos, han sido encontrados juntos con acompañamiento mortuorio en una de las estructuras alojada en los farellones y siendo el contexto cronológico correspondiente a la ocupación incaica en la región. Es probable que estos individuos tuvieran acceso a herbívoros pastando a la altura en la que se emplaza el yacimiento, mientras que el resto de los individuos analizados pudieron basar su dieta en herbívoros con patrones de desplazamiento a cotas altitudinales mayores. De todos modos, nuevamente, se debe ampliar la muestra para delinear una tendencia. Por otro lado, es interesante lo que ocurre cuando cruzamos la información isotópica del nitrógeno. Podemos hipotetizar que los valores de los individuos del poblado pudieron verse enriquecidos si su dieta se basó en herbívoros pastando en zonas más áridas respecto de la localidad Doncellas, por ejemplo, a una mayor altitud. Los vegetales, dadas las propiedades mineralógicas del suelo y la necesidad de utilizar fertilizantes (como el guano) en los vegetales de consumo humano, pudieron generar este patrón de gran enriquecimiento. De todos modos, los estudios de los efectos de las prácticas de abono en las bases de las cadenas tróficas en la puna son incipientes, con lo cual podemos proponernos controlar en el futuro si el enriquecimiento en $\delta^{15} \mathrm{~N}$ de estos valores humanos también se explica por el requerimiento de guano para el cultivo.

A pesar de las limitaciones de la muestra ya especificadas anteriormente, es evidente que existe un patrón diferencial que distingue, al menos ergológicamente, al sector del poblado del sector de sepulcros. La diferenciación ergológica que aparece en estos enterratorios no solo está relacionada con los recipientes cerámicos, sino también con otros elementos que podrían considerarse "suntuarios". En el registro del inventario original del $\mathrm{ME}$, fue posible constatar la abundante presencia de este tipo de bienes como por ejemplo keros de madera grabados, collares de cuentas de piedras semipreciosas, tabletas talladas y boquillas inhaladoras, objetos emplumados, estólicas, sonajeros, tumis de cobre o plata, topus de cobre, oro o plata, adornos de oro y plata, valvas de moluscos marinos, etc. Asimismo, a partir del análisis entre lo consumido y lo asimilado mediante la información paleodietaria, hallamos otro ítem (el maíz) que cumplió un rol importante en el vínculo de los vivos con los muertos. Ya no podemos realizar una lectura directa de la jerarquización de lo consumido conforme su presencia en el registro mortuorio. La relevancia del maíz en la localidad arqueológica Río Doncellas, inferida por otros autores a partir de su presencia en el registro mortuorio, pudo deberse al efecto de la reclamación del yacimiento y cuevas aledañas como espacios destinados a prácticas ceremoniales hasta épocas recientes (Pérez de Micou 1996), siendo el acopio de dichos macrorrestos el resultado de las "visitas a los ancestros" y no el simple descarte de lo consumido por los individuos allí enterrados.

Ahora bien, ¿a qué atribuimos estas diferencias? En primera instancia, disentimos con la postura que caracteriza a las sociedades tardías como las que ocuparon Doncellas con fuertes elites controlando la producción y la circulación interregional de bienes, sino que acordamos con la idea que postula un tipo de organización social supradoméstica, que restringía la acumulación económica y el ejercicio del poder político (McGuire y Saitta 1996). Igualmente, esta perspectiva está lejos de concebir a las sociedades del Período Tardío en general y a las que ocuparon este sitio en particular como "igualitarias", sino 


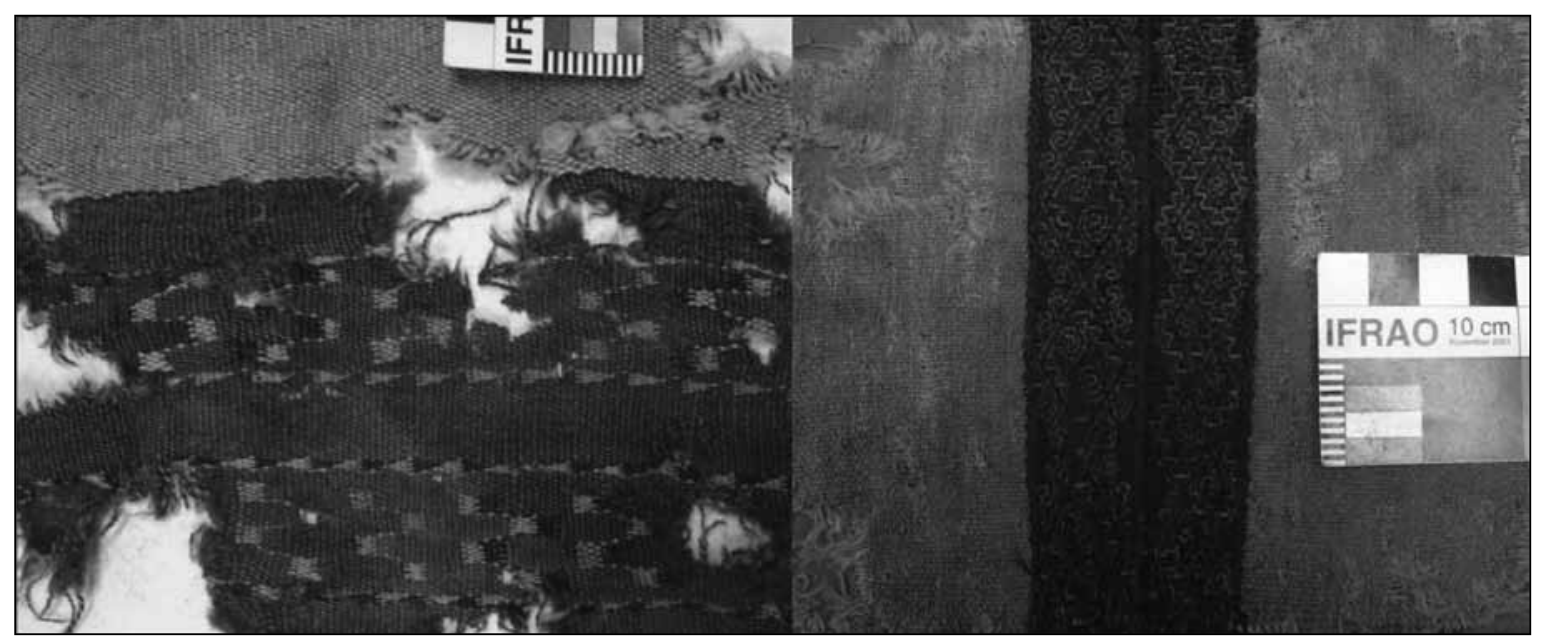

Figura 16. Textiles de Doncellas. Cortesía de López Campeny, colección del ME “Juan B. Ambrosetti” (FFyL, UBA) N $42-662$ y 23136.

que la producción económica pudo ser descentralizada, siendo las autoridades étnicas quienes se apropiaran del trabajo comunal (Nielsen 2006b).

Desde un posicionamiento teórico que asume que los muertos y la muerte constituyen una importante oportunidad para la naturalización de las relaciones de poder (Nielsen 2006b), atribuimos las diferencias encontradas en los patrones mortuorios a un tratamiento diferencial de cierto tipo de personas relacionadas con la producción textil. Esto no necesariamente es reflejo de una apropiación por parte de esos mismos tejedores de la producción durante su vida. Desde esta perspectiva, la cantidad de ítems encontrados en las tumbas se relaciona más con un proceso de valoración por parte de la comunidad hacia esa actividad antes que una situación de poder diferencial ejercida por los individuos que poseen dicho acompañamiento mortuorio.

Es importante, para esta discusión, retomar lo señalado por Yacobaccio y Madero (2001), para quienes este sector geográfico presenta un alto potencial ecológico para la explotación ganadera secundaria, es decir, el transporte y la textilería. En este sentido, y a pesar que ciertas disposiciones culturales se mantienen variables, el componente productivo textil parece ser el que le da identidad a esta área. Nótese que con esta sobrevaloración de la actividad textil que remarcamos, no estamos afirmando que fuera parte de un listado de rasgos limitantes de una "cultura", pues de ese modo estaríamos olvidando los diferentes patrones mortuorios que conviven en la localidad y que yacen en el sector poblado de la misma. Por lo tanto, pensamos a Doncellas como un centro de producción textil especializado. Esta producción pudo no ser a gran escala, administrada y regulada por un grupo o una institución, sino que pudo tener lugar en unidades domésticas ( $\mathrm{Ta}$ rragó 2007, Sullivan 2002, entre otros) y los productos resultantes pudieron satisfacer no solo la demanda interna sino también ser utilizados en las redes de intercambio. Si bien Alfaro de Lanzone visualiza un "taller" de tejedores en el Recinto 2, Sector 1 del poblado, demarcado por la presencia de bowls para hilar y apoyos de telar (Alfaro de Lanzone 1983), nos inclinamos más por nuestra primera posición en la que esta actividad pudo llevarse a cabo en dichas unidades.

En cuanto al análisis paleodietario, si comprendemos a Doncellas como componente del nodo (sensu Haggett 1976 en Nielsen 2006a) del bolsón fértil de la cuenca de Miraflores, identificamos que existe una continuidad, dada la persistencia de una señal isotópica esperable para consumidores del recurso cárnico. ${ }^{4}$ Por otro lado, si bien la presencia de bienes alóctonos concuerda con el posicionamiento de Doncellas como nodo, actuando como articulador de caravanas desde las tierras

\footnotetext{
4 Con valores enriquecidos en $\delta^{15} \mathrm{~N}$ y proteína más enriquecida en el $\delta^{{ }^{13}} \mathrm{C}$ de colágeno que el de apatita.
} 
altas hacia las zonas subandinas y los valles intermedios (Yacobaccio 1979, Perez de Micou 1996), podríamos aceptar la idea que la tejeduría es la actividad que identifica al nodo.

Por lo tanto, lo que interpretamos a partir de los patrones mortuorios, sería el lugar que mantienen los productores dentro de la comunidad. Son entonces estos productores los que tienen un tratamiento especial, es decir que no habría una elite que se apropia sino un sector que produce valor y a su vez es valorado. Esta valoración se materializa en todo el registro mortuorio, pues el mismo presenta una cordelería (Pérez de Micou 1996), una textilería (Rolandi de Perrot 1979) y al menos una cerámica para los muertos, entre otros ítems. En este contexto, retomamos a Pérez de Micou (2001), donde detalla una serie de procedimientos que se realizan a distintos tipos de objetos con el fin de integrar el acompañamiento mortuorio. Inclusive la ubicuidad de especímenes de maíz en las tumbas permite pensar que los mismos cumplieron un rol dentro de la práctica mortuoria más importante que en el simple consumo cotidiano.

Por otra parte, al contabilizar los objetos relacionados con la actividad textil pertenecientes a la colección del ME (cuantificación en base al inventario de las campañas de Casanova en 1942, 1943 y 1944) más del 50\% de los objetos son componentes de esta actividad: husos, torteros, agujas, peines, instrumentos de madera para tejer, bolsas tejidas con retazos de lanas. A esto último hay que sumar la valiosa colección textil que se encuentra en este mismo museo. Entre la cerámica aparecen en redundancia los vasitos chatos, característicos del área puneña, los cuales algunos autores los han relacionado con el oficio de tejer y los denominan vasitos hilanderos (Gatto 1943). Entre los recipientes cerámicos, como ya lo hemos mencionado anteriormente, 69 pertenecen a esta variedad formal y muchos de ellos se presentan con un agujero en el centro el cual se postula podría haber servido para sostener el uso al hilar. Asimismo, otro punto a favor que relaciona a Doncellas con esta actividad son las cestas analizadas por Pérez de Micou (1996), provenientes del sector de tumbas donde esta autora identifica algunas que guardan similitud en su forma general, con las cestas de los enterratorios inkas de mujeres dedicadas a la textilería (Mason 1901 en Pérez de Micou 1996).
En su análisis a los tejidos de Doncellas, Rolandi de Perrot (1979) y Lopez Campeny (2005) reconocen técnicas de manufactura que vincularían a esta actividad con una larga tradición y un amplio dominio de la manufactura textil, como por ejemplo el teñido mediante la técnica de íkat o reserva, las diferentes técnicas de faz y urdimbre como transposición, flotantes o complementarias o la utilización de técnicas superestructurales como bordados y costuras polícromas en sectores especiales de las prendas o en las terminaciones (Figura 16).

Todos estos datos en su conjunto permitirían pensar que, de haberse integrado Doncellas a una estrategia de dominio inkaico, esta pudo ser proveedora de textiles y aquellas personas dedicadas a esta actividad podrían estar recibiendo un tratamiento especial a la hora de sus inhumaciones, hipótesis en la cual trabajaremos en futuras investigaciones.

\section{* Conclusión}

Consideramos este trabajo como una aproximación a los aspectos sociales posibles de ser inferidos a partir del análisis comparativo de los diferentes sectores de Doncellas. Remarcamos que para hacerlo utilizamos la información proveniente de líneas de investigación independientes, lo cual nos ha permitido combinar distintos tipos de datos a la hora de las interpretaciones.

A pesar de las carencias de la muestra, ya mencionadas anteriormente, hemos avanzado en el objetivo de detectar similitudes o diferencias entre los dos sectores de la localidad, así como también hemos iniciado una perspectiva de análisis en el registro isotópico con implicancias paleodietarias, el cual es incipiente dado que aún falta incluir en la discusión valores provenientes de las series esqueletales alojadas en el ME y del IIT.

Asimismo, este no deja de ser un puntapié inicial para un trabajo que permita la confluencia de diferentes abordajes a partir de otros registros materiales, los cuales aportarán datos para las discusiones aquí planteadas. De esta manera podremos profundizar nuestra comprensión sobre los procesos sociales que tuvieron lugar en Doncellas. 
Agradecimientos Este trabajo se desarrolló gracias al respaldo de la FFyL (UBA), CONICET, INAPL e INGEIS. También debemos agradecer al Dr. Daniel Olivera y al Dr. Augusto Tessone por brindar su tiempo para discutir las ideas planteadas en este trabajo. A la dirección y al personal del museo del Instituto Interdisciplinario de Tilcara Dr. Eduardo Casanova FFyL-UBA por el permiso otorga- do para analizar la colección Doncellas allí depositada, y a la dirección y personal del Museo del Hombre del INAPL y del Museo Etnográfico Juan Bautista Ambrossetti FFyLUBA. Por último, queremos agradecer los aportes de dos evaluadores anónimos que enriquecieron el presente manuscrito. Aun así, todas las ideas e interpretaciones del mismo son de nuestra exclusiva responsabilidad.

\section{* Referencias citadas}

ALBECK M. E. 2001 La puna argentina en los períodos medio y tardío. En Historia Argentina Prehispánica, E. Berberián y A. Nielsen (Eds.), pp. 347-388, Editorial Brujas, Córdoba.

ALBECK, M. y M. RUIZ, 2003. El tardío en la Puna de Jujuy: poblados, etnias y territorios. Cuadernos Facultad de Humanidades y Ciencias Sociales, 20: 199-221.

ALFARO DE LANZONE, L. 1983. Investigación Arqueológica en la Cuenca del Río Doncellas (Prov. de Jujuy). Integración de la Puna Jujeña a los Centros Cúlticos Andinos. Relaciones de la sociedad Argentina de Antropología. Tomo XV, Buenos Aires.

1988. Investigación en la Cuenca del Rio Doncellas. Dpto. de Cochinoca pcia. de Jujuy. Reconstrucción de una cultura olvidada en la puna jujeña. Imprenta del Estado de la pcia. de Jujuy, Jujuy.

ALFARO DE LANZONE, L. y J. SUETTA, 1976. Excavación en la cuenca del río Doncellas.Antiquitas XXII-XXIII, Buenos Aires.

AMBROSE, S. H. 1993. Isotopic analysis of paleodiets: Methodological and interpretive considerations. En Investigations of ancient human tissue. Chemical analysis in anthropology, M. K. Sandford (Ed.), pp. 59-130. Gordon and Breach Science Publishers, Pensylvania.

AMBrose, S. H., B. M. BUTLER, D. B. HANSON, R. L. HUNTER-ANDERSON y H. W. KRUEGER, 1997. Stable isotopic analysis of human diet in the Marianas Archipelago, Western Pacific. American Journal of Physical Anthropology 104: 343-361.

AMUNDSON, R., A. T. AUSTIN, E. A. G. SCHUUR, K. YOO, V. MATZEK, C. KENDALL, A. UEBERSAX, D. BRENNER y W. T. BAISDEN, 2003. Global patterns of the isotopic composition of soil and plant nitrogen. Global biogeochemical cycles 17(1): 1031.

AUSTIN, A. T. y P. M. VITOUSEK, 1998. Nutrient dynamics on a rainfall gradient in Haea'i. Oecologia 113: 519-529.

ÁVILA, F. 2008. Un universo de formas, colores y pinturas. Carac- terización del estilo alfarero yavi de la puna nororiental de Jujuy. Intersecciones en Antropología 9: 197-212.

BASILE, M. 2009. Recorriendo trazos. Un aporte a la definición del estilo decorativo Belén. Arqueología 15.

BENNET, W., E. BLEILER y F. SOMMER, 1948. Northwest Argentine Archeology. Yale University. Publications on Anthropology 3: 13-157.

BOCHERENS, H. 2000. Preservations of isotopic signals $\left({ }^{13} \mathrm{C}\right.$, ${ }^{15} \mathrm{~N}$ ) in Pleistocene mammals. En Biogeochemical Approaches to Paleo-dietary Analysis, S. H. Ambrose y M. A. Katzenberg (Eds.), pp. 65-88. Plenum: Advances in Archaeological and Museum Science 5, New York.

BOGAARD, A., T. H. E. HEATON, P. POULTON y I. MERBACH, 2007. The impact of manuring on nitrogen isotope ratios in cereals: archaeological implications for reconstruction of diet and crop management practices. Journal of Archaeological Science 34(3) 335-343.

BUIKSTRA, J. E. y D. H. UBELAKER, 1994. Standards for Data Collection from Human Skeletal Remains Arkansas Archaeological. Survey Research Series 44, Fayetteville.

COLTRAIN, J. B. y W. LEAVITT, 2002. Climate and diet in Fremont prehistory: Economic variability and abandonment of maize agriculture in the Great Salt Lake basin. American Antiquity 67: 1-33.

CABRERA, A. L. 1957. La vegetación de la puna argentina. Revista de investigaciones agrícolas XI (4):317-412.

CASANOVA, E. 1943. Comunicación acerca del Yacimiento de Doncellas. Boletín de la Sociedad Argentina de Antropología, Resúmenes de actividades 5-6, Buenos Aires.

1944. Una estólica de la puna Jujeña. Relaciones de la Sociedad Argentina de Antropología IV: 115-132. 
CORMIE A. B. y H. P. SCHWARCZ, 1996. Effects of climate on deer bone $\delta^{15} \mathrm{~N}$ and $\delta^{13} \mathrm{C}$ : Lack of precipitation effects on $\delta^{15} \mathrm{~N}$ for animals consuming low amounts of $\mathrm{C}_{4}$ plants. Geochimica et Cosmochimica Acta 60 (21): 4161-4166.

DE NIRO, M. J. y S. EPSTEIN, 1981. Influence of diet on the distribution of nitrogen isotopes in animals. Geochimica et CosmochimicaActa 45, pp. 341-351.

EGAÑA, S., M. BORDACH. y O. MENDONCA, 2003. La necrópolis prehispánica de Doncellas (Depto. de Cochinota, Jujuy). Exploración de su potencial interpretativo. Pacarina 3: 121-131.

ELÍAS, A. 2006. Primeros pasos de un plan de manejo para la colección arqueológica Doncellas (INAPL). Cuadernos del INAPL 20:391-397.

FERNÁNDEZ, J.y H. O. PANARELLO, 1999-2001a. Los isótopos estables del carbono en pelo de animales silvestres de ambientes altiplánicos de Argentina. Xama 12-14: 61-69.

1999-20orb. Los isótopos estables del carbono en pelo de animales silvestres de ambientes altiplánicos de Argentina. Xama 12-14: 61-69.

GATTO, E. 1943. Las ruinas del Pucará de Humahuaca. Congreso de Historia Argentina del Norte y Centro I, pp. 130-142, Córdoba.

HEATON, T. H. E. 1987. The ${ }^{15} \mathrm{~N} /{ }^{14} \mathrm{~N}$ ratios of plants in South Africa and Namibia: relationship to climate and coastal/saline enviroments. Oecologia 74(2) 236-246.

JONES, S. 1997. The Archaeology of Ethnicity. Constructing identities in the present and the past. Routledge, New York.

KELLNER, C. y M. SHOENINGER, 2007. A simple carbon isotope model for reconstructing prehistoric human diet. American Journal of Physical Anthropology 133: 1112-1127.

KRAPOVICKAS, P. 1958-1959. Arqueología de la Puna Argentina. Anales de Arqueología y Etnohistoria, Universidad Nacional de Cuyo Tomo XIV-XV: 53-113.

KRUEGUER, H. W. y C. H. SULLIVAN, 1984. Models for carbon isotope fractionation between diet and bone. En: Stable Isotopes in nutrition, J. R. Turnuld y P. E. Johnson (eds.), pp. 205-220. Washington D.C. American Chemical Society Symposium Series.

LÓPEZ CAMPENY, S. 2005. Estructuras, representaciones y contextos. Perspectivas teórico metodológicas para el análisis de textiles arqueológicos. En Tejiendo sueños en el Cono Sur: Textiles Andinos: Pasado, Presente y Futuro, V. Solanilla Demestre (Ed.), pp.
59-82. Grup d'Estudis Precolombins, Universitat Autònoma de Barcelona, Barcelona.

MCGUIRE, R. y D. J. SAITTA, 1996. Although they have petty captains, they obey them badly: the dialectics of Prehispanic Western Pueblo social organization. American Antiquity, 61 (2): 197-216.

MENGONI GOÑALONS, G. L. 2007. Camelid management during Inca times in N. W. Argentina: models and archaezoological indicators. Anthropozoologica 42 (2): 129-141.

MURPHY, B. P. y D. M. J. S. BOWMAN, 2006. Kangaroo metabolism does not cause the relationship between bone collagen $\delta^{15} \mathrm{~N}$ and water availability. Functional Ecology 20 (6): 10621069.

NIELSEN, A. E. 2006a. Estudios internodales e interacción interregional en los Andes circunpuneños: teoría, método y ejemplos de aplicación. En Esferas de interacción prehistóricas y fronteras nacionales modernas: los Andes sur centrales, H. Lechtman (Ed.), pp. 29-62. Instituto de Estudios Peruanos, Institute of Andean Research, Lima.

2006b. Pobres jefes: aspectos corporativos en las formaciones sociales pre-inkaicas de los andes circunpuneños. En Contra la tiranía tipológica en Arqueología: una visión desde Sudamérica, C. Gnecco y C. H. Langebaek (Eds.), pp. 121-150. Universidad de los Andes, Facultad de Ciencias Sociales, CESO, Ediciones Uniandes, Bogotá.

OTTONELLO DE GARCIA REINOSO, M. 1973. Instalación económica y cambio cultural en el sitio tardío de Agua Caliente de Rachaite. Publicaciones Dirección de Antropología e Historia, Jujuy.

\section{OTTONELLO DE GARCÍA REINOSO, M. y P. KRAPOVICKAS,} 1973. Ecología y arqueología del sector oriental de la Puna. Publicación, 1:3-21.

OTTONELLO DE GARCÍA REINOSO, M. y B. RUTHSATZ. 1982. Environment, human settlement, and agricultura in the Puna de Jujuy, Argentina. A case study of land-use change. Mountain Research and Development 2 (1): 111-126.

PATE, F. D. 1994. Bone Chemistry and Paleodiet. Journal of Archaeological Method and Theory 1: 161-209.

PÉREZ DE MICOU, C. 1996. Los artefactos sobre matérias primas vegetales de la Colección Doncellas, Museo Etnográfico (Buenos Aires) y Museo del Pucará (Tilcara). Tesis de doctorado, Universidad de Buenos Aires.

1998. Las colecciones arqueológicas y la investigación. Revista do Museu de Arqueologia e Etnologia 8: 223-233. 
2001. Cestería y cordelería para los muertos. Chungara (Arica) 33: 137-144.

PÉREZ, M. 2008. Nueva aproximación al estudio del material cerámico del yacimiento arqueológico del río Doncellas (Depto. de Cochinota, prov. de Jujuy). Tesis de licenciatura, Universidad de Buenos Aires.

2009. Análisis comparativo de los conjuntos cerámicos de colecciones de museo: el caso Doncellas. Entre pasados y presentes III. En prensa.

RICE, P. 1987. Pottery Analysis: A Sourcebook. University of Chicago Press, Chicago.

RUTHSATZ, B. y C. P. MOVIA, 1975. Relevamiento de las estepas andinas del noroeste de la provincia de Jujuy. FECIC, Buenos Aires.

RYE, O. 1981. Approaches to Archaeological Ceramics. Plenum Press, New York.

ROLANDI DE PERROT, D. 1979. Los tejidos del Río Doncellas. Dpto. Cochinoca. Jujuy. Jornadas de Arqueología del N.O.A. Antiquitas 2: 22-73.

SAMEC, C. 2011. Perspectiva isotópica sobre la alimentación de camélidos domésticos y silvestres de la Puna Jujeña: construyendo un marco de referencia para estudios arqueológicos. Tesis de licenciatura, Facultad de Filosofía y Letras.

SCHOENINGER, M. J. 1995. Stable Isotopes Studies in Human Evolution. Evolutionary Anthropology 4(3): 83-98.

SEALY, J. C., N. J. VAN DER MERWE, J. A. LEE THORP y J. L. LANHAM, 1987. Nitrogen isotopic ecology in southern Africa: Implications for environmental and dietary tracing. Geochimica et Cosmochimica Acta 51(10): 2707-2717

SQUEO, F. A. y J. R. EHLERINGER, 2004. Isótopos estables: una herramienta común para la ecofisiología vegetal y animal. En Fisiología Ecológica en Plantas: Mecanismos y Respuestas a Estrés en los
Ecosistemas, H. M. Cabrera (Ed.), pp. 59-80. Ediciones Pontificia Universidad Católica de Valparaíso, Valparaíso.

SULLIVAN, K. 2002. Specialized Production of San Martín Orange Ceramics in the Tlajinga District of Classic Period Teotihuacán, México. Tesis de magíster, Department of Anthropology, Arizona State University, Tempe.

TARRAGÓ, M. 2007. Ámbitos domésticos y de producción artesanal en el Noroeste Argentino prehispánico. Intersecciones en Antropología 8: 87-100.

TIESZEN, L. L. 1991. Natural variations in the Carbon Isotope Values of plants: implications for archaeology, ecology and paleoecology. Journal of Archaeological Science 18: 227-248.

VAN KLINKEN, G. J. 1999. Bone collagen quality indicators for paleodietary and radiocarbon measurements. Journal of Archaeological Science 26: 687-695.

VIGNATI, M. A. 1938. Novíssima Veterum. Hallazgo en la Puna Jujeña. Revista del Museo de la Plata. Tomo I. Sección Antropología.

YACOBACCIO, H. D. 1979. Arte rupestre y tráfico de caravanas en la Puna de Jujuy: modelo e hipótesis. Antiquitas 2:392-407.

YACOBACCIO, H. D., y C. MADERO, 20o1. Ethnoarchaeology of a Pastoral Settlement of the Andean Plateau: An investigation of Archaeological scale. En Ethnoarchaeology of Andean South America: contributions to archaeological method and theory, L. A. Kuznar (Ed.), pp. 84-96. International Monographs in Prehistory Ann Arbor, Michigan.

YACOBACCIO, H. D., C. T. SAMEC y M. P. CATÁ, 2010. Isótopos estables y zooarqueología de camélidos en contexto pastoriles de la puna (Jujuy, Argentina). En Zooarqueología a principios del siglo XXI: Aportes teóricos, metodológicos y casos de estudio, M. A. Gutiérrez, M. De Nigris, P. M. Fernández, M. Giardina, A. Gil, A. Izeta, G. Neme y H. Yacobaccio (Eds.), pp. 77-86. Ediciones del Espinillo, Buenos Aires. 